\title{
The Zygosaccharomyces bailii transcription factor Haa1 is required for acetic acid and copper stress responses suggesting subfunctionalization of the ancestral bifunctional protein Haa1/Cup2
}

Margarida Palma, Paulo Jorge Dias, Filipa de Canaveira Roque, Laura Luzia, Joana Fernandes Guerreiro and Isabel Sá-Correia ${ }^{*}$

\begin{abstract}
Background: The food spoilage yeast species Zygosaccharomyces bailii exhibits an extraordinary capacity to tolerate weak acids, in particular acetic acid. In Saccharomyces cerevisiae, the transcription factor Haa1 (ScHaa1) is considered the main player in genomic expression reprogramming in response to acetic acid stress, but the role of its homologue in Z. bailii (ZbHaa1) is unknown.

Results: In this study it is demonstrated that ZbHaa1 is a ScHaa1 functional homologue by rescuing the acetic acid susceptibility phenotype of S. cerevisiae haa1A. The disruption of ZbHAA1 in Z. bailii IST302 and the expression of an extra ZbHAA1 copy confirmed ZbHAA1 as a determinant of acetic acid tolerance. ZbHaa1 was found to be required for acetic acid stress-induced transcriptional activation of $Z$. bailii genes homologous to ScHaa1-target genes. An evolutionary analysis of the Haa1 homologues identified in 28 Saccharomycetaceae species genome sequences, including $Z$ bailii, was carried out using phylogenetic and gene neighbourhood approaches. Consistent with previous studies, this analysis revealed a group containing pre-whole genome duplication species Haa1/Cup2 single orthologues, including ZbHaa1, and two groups containing either Haa1 or Cup2 orthologues from post-whole genome duplication species. S. cerevisiae Cup2 (alias Ace1) is a transcription factor involved in response and tolerance to copper stress. Taken together, these observations led us to hypothesize and demonstrate that ZbHaa1 is also involved in copper-induced transcriptional regulation and copper tolerance.
\end{abstract}

Conclusions: The transcription factor ZbHaa1 is required for adaptive response and tolerance to both acetic acid and copper stresses. The subfunctionalization of the single ancestral Haa1/Cup2 orthologue that originated Haa1 and Cup2 paralogues after whole genome duplication is proposed.

Keywords: Yeast, Haa1, Cup2/Ace1, Acetic acid response and tolerance, Copper response and tolerance, Subfunctionalization, Transcription factors

\footnotetext{
* Correspondence: isacorreia@tecnico.ulisboa.pt

iBB-Institute for Bioengineering and Biosciences, Department of

Bioengineering, Instituto Superior Técnico, Universidade de Lisboa, 1049-001

Lisbon, Portugal
}

\section{$\int$ Biomed Central}

(c) The Author(s). 2017 Open Access This article is distributed under the terms of the Creative Commons Attribution 4.0 International License (http://creativecommons.org/licenses/by/4.0/), which permits unrestricted use, distribution, and reproduction in any medium, provided you give appropriate credit to the original author(s) and the source, provide a link to the Creative Commons license, and indicate if changes were made. The Creative Commons Public Domain Dedication waiver (http://creativecommons.org/publicdomain/zero/1.0/) applies to the data made available in this article, unless otherwise stated. 


\section{Background}

The Saccharomyces cerevisiae transcription factor Haa1 was first identified based on the DNA binding domain (DBD) homology with the copper-regulated transcription factor Cup2 (alias Ace1) DBD [1]. The paralogue pair Haa1 and Cup2 DBDs comprise 123 and 124 amino acid residues, respectively, at the $\mathrm{N}$-terminal and include a conserved zinc module and a set of four cysteinecysteine clusters organized in a consensus sequence that forms the copper regulatory domain (CuRD). Such conservation at the level of the DNA binding domains led to hypothesize that, like Cup2, Haa1 could play a role in copper homeostasis; however, metalloregulation and involvement of Haa1 in $S$. cerevisiae tolerance to copper could not be assigned to this transcription factor [1]. Indeed, no physiological function could be ascribed to Haa1 until the description, by our laboratory, of the essential role of Haa1 in $S$. cerevisiae adaptation and tolerance to weak acids, especially to the short-chain hydrophilic acetic and propionic acids [2].

$S$. cerevisiae Haa1 is considered the main player in yeast genomic expression reprogramming in response to acetic acid stress, being involved in the direct, or indirect, transcriptional activation of approximately $80 \%$ of the acetic acid-responsive genes, several of which required for maximum tolerance to this weak acid [3, 4]. The Haa1 target genes are involved in transcription, multidrug resistance, cell wall remodelling, metabolism of lipids, carbohydrates and amino acids, and nucleic acid processing $[2,4]$. Haa1 binds, in vivo, to an acetic acid responsive element (ACRE) in the promoter of its target genes [5]. Among these genes are TPO2 and TPO3 that code for two plasma membrane transporters of the Major Facilitator Superfamily proposed to mediate the efflux of acetate from the cell interior in acetic acid challenged yeast cells [2, 4, 5]. Other genes of the Haa1 regulon that are required for tolerance to acetic acid [1, 4], include: YGP1 (cell wall-related secretory glycoprotein, [6]), YRO2 (plasma membrane protein with a putative role in acetic acid tolerance [7]), HRK1 (a protein kinase of a family related with the phosphorylation of membrane proteins and implicated in activation of the activity of plasma membrane $\mathrm{H}^{+}$-ATPase Pma1 [8]) and HSP3O (a plasma membrane heat shock protein proposed as a negative regulator of Pma1 [9]). The involvement of Haa1 in $S$. cerevisiae adaptation and tolerance to acetic acid stress has been demonstrated [2, 4, 5], but the function of Zygosaccharomyces bailii Haa1 homologue remains unknown. However, this yeast species is highly problematic in the spoilage of acidic food and beverages due to its remarkable capacity to tolerate acetic acid and other weak acid food preservatives [10]. Although the mechanisms underlying the response and extreme tolerance of $Z$. bailii to acetic acid are still poorly characterized, a number of relevant physiological strategies have been reported. These include the capacity of the yeast cells to tolerate shortterm intracellular $\mathrm{pH}$ changes [11, 12], co-consume acetic acid and glucose [13-15] and exhibit high basal level of complex sphingolipids proposed to decrease plasma membrane permeability to this weak acid [16]. Also, a recent genome-wide study identified the $Z$. bailii transcription factor ZbMsn4 [17], homologous to the $S$. cerevisiae stress-responsive transcriptional activators Msn4 and Msn2 [18], as an acetic acid tolerance determinant. Other tolerance determinant genes, homologous to S. cerevisiae GYP8 and WSC4 (cellular transport and transport routes), PMT1, KTR7 and RKR1 (protein fate), TIF3 (protein synthesis) and ILV3 (amino acid metabolism) were also singled out in the same study [17]. In S. cerevisiae, MSN2 was found to be an acetic acid tolerance determinant [3], and MSN4 is among the genes activated by Haa1 in response to acetic acid stress [4].

Based on the amino acid sequence similarity of Haa1 and Cup2 DBDs, Keller et al. [1] proposed that $H A A 1$ and CUP2 are paralogues. The concept that this paralogy relationship originated in the whole genome duplication (WGD) event was first proposed by Dietrich and co-authors [19], and independently confirmed upon the release of the Yeast Gene Order Browser (YGOB) $[20,21]$, a database dedicated to the assignment of an orthology/ohnology classification to WGD-originated genes in the Saccharomycetaceae family. Although the identification of the orthologue/ ohnologue status is important to trace the evolutionary history of a particular gene family, there are other forces driving the evolution of genes and genomes, as for example local duplications, horizontal gene transfer, gene loss and gain and gene conversion. Understanding the origin of those variations requires the identification of the complete set of bona fide members of a gene family and the integration of different in silico approaches, such as phylogeny and gene neighbourhood analysis.

In the present study we investigate the function of $Z$. bailii gene $Z b H A A 1$ using functional and evolutionary approaches. Using a blastp network traversal approach to perform a global analysis of all the ORFs encoded in the publicly available genomes of 28 Saccharomycetaceae yeast species, a group of amino acid sequences was identified as showing strong sequence similarity to $S$. cerevisiae Haal amino acid sequence. The function of the sole ZbHAA1 encoded in the genome sequences of $Z$. bailii strains CLIB $213^{\mathrm{T}}$ (mentioned herein as ZYBA_3_9_I00670) [22] and IST302 (ORF ZBIST_2620) (Palma M et al.: Genome 
sequence of the highly weak-acid-tolerant Zygosaccharomyces bailii IST302, amenable to genetic and physiological manipulations, unpublished) was examined. Z. bailii strain IST302 has recently been used by our laboratory because, contrasting with the hybrid strain ISA1307 and Z. bailii CLIB $213^{\mathrm{T}}$, it is more prone to genetic engineering and physiological studies ([17], Palma M et al.: Genome sequence of the highly weak-acid-tolerant Zygosaccharomyces bailii IST302, amenable to genetic and physiological manipulations, unpublished). Phylogenetic and gene neighbourhood analyses of the amino acid sequences of the Haal homologues identified in Saccharomycetaceae yeasts, led us to confirm that, upon the WGD event [23], the single transcription factor encoded in the protoploid ancestor yeast species has evolved into two distinct gene sub-lineages, each corresponding to the homologues of S. cerevisiae HAA1 and CUP2 genes in post-WGD species. In this work we experimentally tested the possibility that both HAA1 and CUP2 genes have arisen from the subfunctionalization of the ancestral HAA1/CUP2 orthologue after the WGD event.

\section{Methods}

\section{Strains and growth media}

The prototrophic strains Zygosaccharomyces bailii IST302 [17] and the type strain Z. bailii ATCC58445 ${ }^{\mathrm{T}}$ (=CLIB $213^{\mathrm{T}}$ ) [22] were used in this work. Auxotrophic strains Saccharomyces cerevisiae BY4741 (MATa, his3 $\Delta 1$, leu2 $\Delta 0$, met $15 \Delta 0$, ura $3 \Delta 0)$ and derived deletion mutants haa1 $\Delta$ and cup $2 \Delta$ were obtained from the EUROSCARF collection. Prototrophic yeast strains were batch-cultured at $30^{\circ}$ $C$ with orbital agitation $(250 \mathrm{rpm})$ in liquid mineral medium (MM) that contains, per litre, $1.7 \mathrm{~g}$ yeast nitrogen base without amino acids or $\left(\mathrm{NH}_{4}\right)_{2} \mathrm{SO}_{4}$ (Difco), $20 \mathrm{~g}$ D-glucose (Merck) and $2.65 \mathrm{~g}\left(\mathrm{NH}_{4}\right)_{2} \mathrm{SO}_{4}$ (Merck). S. cerevisiae auxotrophic strains were cultured in MM4 medium, prepared using MM medium supplemented with $20 \mathrm{mg}$ methionine, $20 \mathrm{mg}$ histidine, $60 \mathrm{mg}$ leucine and $20 \mathrm{mg}$ uracil (all from Sigma). Yeast cells used for yeast transformation experiments were cultured in YPD medium ( $1 \%$ yeast extract, Difco, 2\% peptone, Difco, and 2\% D-glucose, Merck). For $Z$. bailii transformants recovery, cells were grown in YPF medium (2\% D-fructose, Amresco, 1\% yeast extract, Difco, and $2 \%$ peptone, Difco). Transformant selection after disruption of $Z b H A A 1$ in the chromosome, or after transformation of Z. bailii IST302 with an extra copy of ZbHAA1, was performed in plates containing YPF supplemented with $200 \mu \mathrm{g} / \mathrm{mL}$ G418. Selection of transformants from the derived auxotrophic $S$. cerevisiae strains was based on growth in MM4 without uracil supplementation. Escherichia coli XL1-Blue was used for plasmid maintenance and general cloning procedures. E. coli cells were grown in LuriaBertani medium (LB), supplemented with $150 \mathrm{mg} / \mathrm{L}$ ampicillin when required. Solid media were obtained by adding
$20 \mathrm{~g}$ of agar to each litre of the corresponding liquid media. All strains were maintained at $-80{ }^{\circ} \mathrm{C}$ in appropriate media supplemented with $15 \%$ glycerol $(\mathrm{v} / \mathrm{v})$.

\section{ZbHAA1 and SCHAA1 cloning into PGREG506}

The nucleotide sequences of ZbHAA1 from $Z$. bailii IST302 (ZBIST_2620) and CLIB 213 ${ }^{\mathrm{T}}$ (ZYBA_3_9_I00670) were obtained from the corresponding genome sequences (Palma $\mathrm{M}$ et al.: Genome sequence of the highly weak-acidtolerant Zygosaccharomyces bailii IST302, amenable to genetic and physiological manipulations, unpublished, and Galeote et al. [22], respectively). The pGREG506 vector from the DRAG \& DROP collection [24] was used to individually clone by homologous recombination and expression of the ORFs ZBIST_2620, ZYBA_3_9_I00670 and ScHAA1, all under the control of the same promoter region, the ScHAA1 promoter region. The cloning vector pGREG506 was acquired from EUROSCARF and contains a HIS3 gene under the control of a galactose inducible promoter (GAL1) and the yeast selectable marker URA3. The homologous recombination was performed in two steps comprising, first, the cloning of ScHAA1 promoter into pGREG506 and, second, the cloning of ScHAA1 or $Z b H A A 1$ into the recombinant vector obtained during the first step. ScHAA1 promoter was amplified from strain BY4741 using the primers ScHAA1prom-F and ScHAA1prom-R (Additional file 1). The amplified ScHAA1 promoter and pGREG506 digested with SpeI and SacI restriction enzymes, i.e. pGREG506 without the GAL1 promoter, were co-transformed into S. cerevisiae BY4741 parental strain and a recombinant plasmid (pGREGpromScHAA1) was obtained through homologous recombination in yeast. Correct cloning of the promoter was confirmed by DNA sequencing. The ORFs ZBIST_2620, ZYBA_3_9_I00670 and ScHAA1 were amplified from $Z$. bailii IST302, Z. bailii CLIB $213^{\mathrm{T}}$ and S. cerevisiae BY4741 genomic DNA, respectively, using the corresponding pair of primers ZbHAA1rec-F/ZbHAA1rec-R and ScHAA1recF/ScHAA1rec-R (Additional file 1). Each of the amplified ORFs was co-transformed into S. cerevisiae BY4741 with the recombinant vector pGREGpromScHAA1 linearized with SalI (i.e. with the HIS3 gene removed). Correct cloning of the genes into the recombinant plasmids was confirmed by DNA sequencing. These plasmids, named here as pG_ScHAA1, pG_ZbHAA1-IST and pG_ZbHAA1-CL, containing, respectively, ScHAA1 or ZbHAA1 homologue from strain IST302 or strain CLIB $213^{\mathrm{T}}$, were then transformed into $S$. cerevisiae haa1s deletion mutant. pG_ScHAA1 and pG_ZbHAA1-IST were also transformed in cup $2 \Delta$ deletion mutant. Additionally, S. cerevisiae BY4741 parental, haa $1 \Delta$ and cup $2 \Delta$ were transformed with the cloning vector pGREG506 with the HIS3 gene deleted (pGREG506_noHIS3) that was previously constructed and reported as the correct empty vector to be used as control 
[17] since in the recombinant vectors the HIS3 gene is substituted by the insert of interest.

\section{Disruption of Z. bailii IST302 HAA1 homologue}

a) Construction of ZbHAA1 disruption cassette

The disruption of $Z$. bailii IST302 ZbHAA1 (ORF ZBIST_2620) was performed by homologous recombination of a $Z b H A A 1$ disruption cassette into the chromosome. The disruption cassette was obtained by a three step-based fusion of DNA fragments generated by polymerase chain reaction (PCR) $[25,26]$. All PCR reactions were performed with Taq Phusion High-Fidelity DNA Polymerase (Thermo Scientific) following the manufacturer's instructions. In the first step three primary PCR reactions were carried out. The amplification of fragments haala and haalb was obtained by using the pair of primers haala-1/haala-2 and haalb-3/ haalb-4, respectively, with Z. bailii IST302 genomic DNA as a template. The kan cassette DNA fragment was amplified from the centromeric plasmid $\mathrm{pZ}_{3} b \mathrm{~T}$ [27] using the pair of primers kan-5/kan-6 (Additional file 1). These primers were carefully designed in order to have identical melting temperatures. Accordingly, the same annealing temperature $\left(56{ }^{\circ} \mathrm{C}\right)$ was used in all PCR reactions. The amplified DNA fragments haala, haalb and kan cassette were analysed in a $0.8 \%$ agarose (NZYTech) gel electrophoresis and its molecular weight confirmed by comparison with $1 \mathrm{~kb}$ Plus DNA Ladder (Invitrogen). The DNA fragments were then directly extracted and purified from the agarose gel using JETQUICK gel extraction spin kit (Genomed) according to manufacturer's instructions. In the second and third steps we followed the methodology described by Shevchuk et al. [26] with minor modifications. Basically, a PCR reaction of 12 cycles was carried out without primers and containing approximately $100 \mathrm{ng}$ of haala, $100 \mathrm{ng}$ of haalb and $30 \mathrm{ng}$ of kan cassette. Subsequently, a total of $3 \mu \mathrm{L}$ of this PCR product was used as a template for another PCR reaction (total volume of $20 \mu \mathrm{L}$ ) containing the primers haala-1 and haalb-4 (Additional file 1). The resulting $2.7 \mathrm{~kb}$ PCR product was analysed by electrophoresis in $0.8 \%$ agarose, extracted and purified as mentioned above. The methodology was performed several times to obtain $0.5-1 \mu \mathrm{g}$ of DNA that was subsequently used for transformation of $Z$. bailii IST302 cells.

b) Transformation of $Z$. bailii IST302 and homologous recombination of $Z b H A A 1$ disruption cassette in the chromosome

The transformation of Z. bailii IST302 was performed with Alkali-Cation ${ }^{\text {TM }}$ Yeast Transformation kit (MP Biomedicals) introducing minor modifications to the manufacturer's protocol. Specifically, cells were cultivated overnight in YPD medium, at $30{ }^{\circ} \mathrm{C}$ and $250 \mathrm{rpm}$, and then reinoculated at an absorbance of 0.1 at $600 \mathrm{~nm}$ in $50 \mathrm{ml}$ of fresh medium. Cells were grown until mid-exponential phase (absorbance of $1.0 \pm 0.1$ at $600 \mathrm{~nm}$ ) and a total of $1.5 \times 10^{8}$ cells were collected by centrifugation. All centrifugation steps were carried out during $10 \mathrm{~min}$ at $4000 \mathrm{rpm}$ $\left(4{ }^{\circ} \mathrm{C}\right)$. A total of $0.5-1 \mu \mathrm{g}$ of the $H A A 1$ disruption cassette was added to the transformation mixture. The transformation reaction was incubated during $30 \mathrm{~min}$ at $30{ }^{\circ} \mathrm{C}$, followed by a heat-shock at $42{ }^{\circ} \mathrm{C}$ during $40 \mathrm{~min}$. Transformed cells were then centrifuged, resuspended in YPF containing $1 \mathrm{M}$ sorbitol (Sigma) and incubated overnight at $30{ }^{\circ} \mathrm{C}$ for recovery. Yeast recombinant clones were selected in YPF plates containing $200 \mu \mathrm{g} / \mathrm{mL}$ G418 (Sigma).

\section{Cloning and expression of an extra copy of $Z b H A A 1$ in $Z$. bailii IST302}

The expression of an extra copy of $Z b H A A 1$ gene in the parental strain Z. bailii IST302 was performed by cloning this ORF by homologous recombination into the centromeric expression vector $\mathrm{pZ}_{3} b \mathrm{~T}$ [27] linearized with XbaI. The amplification of ZbHAA1 and of its corresponding promoter (approximately $1000 \mathrm{bp}$ upstream the start codon) from $Z$. bailii IST302 genomic DNA was performed using the primers ZbHAA1pZ-F, ZbHAA1pZ-R (Additional file 1). The amplified product was co-transformed with the linearized $\mathrm{pZ}_{3} b \mathrm{~T}$ into $S$. cerevisiae BY4741. Selection of the transformants harbouring the recombinant vector $\mathrm{pZ}_{3} b \mathrm{~T}_{-}$ZbHAA1 was performed in YPD plates containing G418 $(200 \mu \mathrm{g} / \mathrm{mL})$. The correct recombination was confirmed by sequencing the obtained plasmids. The recombinant plasmids and the cloning plasmid were used to transform $Z$. bailii IST302, as previously described.

\section{Susceptibility assays in liquid media}

Susceptibility assays in liquid media were assessed by comparing yeast growth curves obtained by periodic measurements of culture absorbance at $600 \mathrm{~nm}$. Yeast cells were pre-cultured in the appropriate unsupplemented medium until mid-exponential phase (standard absorbance of $0.5 \pm 0.05)$ and then reinoculated at an initial absorbance of 0.05 , in $50 \mathrm{ml}$ of the fresh medium, supplemented or not with acetic acid. All assays were carried at $30{ }^{\circ} \mathrm{C}$ with orbital agitation $(250 \mathrm{rpm})$. Different growth media were used according to strains' nutritional requirements. The susceptibility to acetic acid of S. cerevisiae parental strain BY4741 and the derived deletion mutant haa1s, harbouring each of the recombinant plasmids produced in this study was assessed in liquid MM4-U medium, $\mathrm{pH}$ 4.0, either or not supplemented with $60 \mathrm{mM}$ or $75 \mathrm{mM}$ acetic acid. Acetic acid susceptibility assays involving $Z$. bailii strains were 
performed in liquid $\mathrm{MM}$ medium, $\mathrm{pH} 4.0$, either or not supplemented with 180 and $220 \mathrm{mM}$ acetic acid.

\section{Susceptibility assays in solid media}

Yeast cells were pre-cultured overnight in the appropriate unsupplemented liquid medium and then reinoculated at an absorbance at $600 \mathrm{~nm}$ of 0.05 , in $50 \mathrm{ml}$ of fresh medium. When the cultures reached an absorbance of $0.5 \pm 0.05$ at $600 \mathrm{~nm}$ cells were resuspended in sterile water to obtain suspensions with an absorbance of $0.05 \pm 0.005$. These cell suspensions and three subsequent dilutions $(1: 5 ; 1: 10 ; 1: 20)$ were applied as $4 \mu \mathrm{L}$ spots onto the surface of agarized media, supplemented, or not, with increasing concentrations of the compound to be tested and incubated at $30{ }^{\circ} \mathrm{C}$ for 3 to 5 days. In the case of $Z$. bailii IST302 parental and derived Zbhaa1A deletion mutant strains, as well as $Z$. bailii IST302 expressing an extra copy of ZbHAA1 ( $\mathrm{pZ}_{3} b \mathrm{~T}$ ZZbHAA1) or the cloning vector $\left(\mathrm{pZ}_{3} b \mathrm{~T}\right)$ susceptibility to acetic, benzoic and sorbic acids and copper was compared in MM medium, at $\mathrm{pH}$ 4.5. Regarding $S$. cerevisiae BY4741 parental and derived deletion mutants haa $1 \Delta$ and cup $2 \Delta$ or this cup $2 \Delta$ mutant transformed with the recombinant plasmids produced herein, susceptibility assays were assessed in MM4 or MM4-U media, respectively, at $\mathrm{pH} 4.5$.

\section{Comparison of mRNA relative levels by real time RT-PCR}

The effect of the expression of ZbHAA1 in the mRNA levels from $S$. cerevisiae Haa1- or Cup2- target genes under acetic acid or copper stresses, respectively, was assessed by expressing the recombinant plasmids pG_ZbHAA1-IST, pG_ScHAA1 and the cloning vector either in S. cerevisiae haa $1 \Delta$ or cup $2 \Delta$ deletion mutants. S. cerevisiae BY4741 parental strain transformed with the empty vector was used as a positive control. The effect of ZbHAA1 in Z. bailii IST302 transcriptional response to acetic acid was also assessed by comparing the mRNA levels from $Z$. bailii genes homologous to $S$. cerevisiae Haa1-regulon genes in cells of $Z$. bailii IST302 parental and derived deletion mutant Zbhaald strains, in the presence and absence of appropriate concentrations of acetic acid. In both assays, yeast cells were cultivated in the appropriate media until mid-exponential phase (standard absorbance at $600 \mathrm{~nm}$ of $0.6 \pm 0.05$ ) and then reinoculated (initial absorbance of $0.2 \pm 0.01$ ) in $500 \mathrm{~mL}$ unsupplemented media. After $1 \mathrm{~h}$ of growth $100 \mathrm{~mL}$ of cell culture were collected and set as the control condition (Time point 0 ); simultaneously, acetic acid or copper were added to the remaining $400 \mathrm{~mL}$ of cell culture. A total of $100 \mathrm{~mL}$ of acetic acid- or copperstressed cells were harvested 1 and $2 \mathrm{~h}$ after the addition of acetic acid or copper (Time points 1 and 2). Cells were collected by centrifugation $(8000 \mathrm{rpm}, 10 \mathrm{~min})$ at
$4{ }^{\circ} \mathrm{C}$, washed twice with cold water and the pellets were frozen in liquid nitrogen and kept at $-80{ }^{\circ} \mathrm{C}$ until RNA extraction. Gene transcript levels were assessed by real time RT-PCR. Extraction of total RNA was performed using a modified hot phenol method [28]. Purification of RNA and DNA digestion with DNAse was performed using the commercial kit Nucleospin - RNA (Macherey-Nagel, Germany). Synthesis of cDNA from total RNA samples was performed using the MultiscribeTM reverse transcriptase kit (Applied Biosystems) and the subsequent Real Time PCR step was carried out using SYBR_Green reagents and 7500 Real Time PCR System (Applied Biosystems). Specific primers were designed in Primer Express Software (Applied Biosystems) using gene sequences obtained from Z. bailii IST302 genome sequence (Palma M et al.: Genome sequence of the highly weak-acid-tolerant Zygosaccharomyces bailii IST302, amenable to genetic and physiological manipulations, unpublished) (Additional file 2) or S. cerevisiae genome database (http://www.yeastgenome.org/). The primer sequences are listed in Additional file 1. Relative values obtained for the expression of each gene either in Z. bailii IST302 parental strain or in S. cerevisiae BY4741 transformed with the cloning vector cultivated in control conditions (Time point 0 ) were set as 1 and the remaining values are presented relative to that sample. Relative gene expression between the conditions tested was calculated according to the $2^{-\Delta \Delta C t}$ method [29] using either ACT1 or ZbACT1 (in the case of S. cerevisiae or Z. bailii strains, respectively) as an internal control for input cDNA normalization. Experiments were performed, at least, three times. Results were analysed by two-way ANOVA, considering a $p$-value below 0.05 , when comparing the relative mRNA levels in each strain at a given time point.

\section{Identification of the putative Haa1/Cup2 homologues encoded in the genomes of the Saccharomycetaceae yeast species}

The translated ORFs of the 33 sequenced hemiascomycetous yeast strains analysed in this work (Additional file 3) were retrieved from their corresponding genome databases (Table 1) and were compiled in the in-house Genome DB. These 33 hemiascomycetous strains correspond to 28 different species, all taxonomically classified in the Saccharomycetaceae family, in particular the genome sequences of Z. bailii CLIB $213^{\mathrm{T}}$ and Z. bailii IST302 (to be soon released) [30]. Henceforth, the four letters code shown in Table 1 for species abbreviation will be used to designate both yeast genes and species. The number displayed after the first four letters is used to abbreviate the strain name when the genome of more than one strain from a given species is available. To standardize the annotation used, translated ORFs are represented with small letters. The comparative genomics approach used in this study is based on the sequence clustering of all translated ORFs of the 33 
Table 1 Saccharomycetaceae yeast strains examined in this work

\begin{tabular}{|c|c|c|c|c|c|c|c|}
\hline $\begin{array}{l}\text { Position in } \\
\text { respect to WGD }\end{array}$ & $\begin{array}{l}\text { Taxonomic genus in } \\
\text { the Saccharomycetaceae } \\
\text { family }\end{array}$ & Species & Strain & $\begin{array}{l}\text { Name } \\
\text { acronym }\end{array}$ & $\begin{array}{l}\text { Genome } \\
\text { Database }\end{array}$ & $\begin{array}{l}\text { Genome Annotation } \\
\text { Tool/Source }\end{array}$ & $\begin{array}{l}\text { Total number } \\
\text { of Haa1/Cup2 } \\
\text { homologues }\end{array}$ \\
\hline \multirow[t]{19}{*}{ Post-WGD } & \multirow[t]{9}{*}{ Saccharomyces } & \multirow{2}{*}{$\begin{array}{l}\text { Saccharomyces } \\
\text { cerevisiae }\end{array}$} & S288c & sace_1 & SGD & SGD & 2 \\
\hline & & & cen.pk113-7d & sace_3 & Genbank & YGAP & 2 \\
\hline & & $\begin{array}{l}\text { Saccharomyces } \\
\text { paradoxus }\end{array}$ & $\begin{array}{l}\text { Consensus of } \\
\text { genome sequences }\end{array}$ & sapa_1 & Sanger & YGAP & 2 \\
\hline & & $\begin{array}{l}\text { Saccharomyces } \\
\text { mikatae }\end{array}$ & IFO 1815 & sami_1 & YGOB & YGOB & 2 \\
\hline & & $\begin{array}{l}\text { Saccharomyces } \\
\text { kudriavzevii }\end{array}$ & IFO 1802 & saku_1 & YGOB & YGOB & 2 \\
\hline & & $\begin{array}{l}\text { Saccharomyces } \\
\text { arboricola }\end{array}$ & $\mathrm{H}-6$ & saar_1 & Genbank & YGOB & 2 \\
\hline & & \multirow{2}{*}{$\begin{array}{l}\text { Saccharomyces } \\
\text { bayanus }\end{array}$} & $623-6 C$ & saba_1 & $S G D$ & YGAP & 2 \\
\hline & & & MCYC 623 & saba_2 & SGD & YGAP & 2 \\
\hline & & $\begin{array}{l}\text { Saccharomyces } \\
\text { uvarum }\end{array}$ & CBS 7001 & sauv_1 & YGOB & YGOB & 2 \\
\hline & \multirow[t]{2}{*}{ Kazachstania } & $\begin{array}{l}\text { Kazachstania } \\
\text { africana }\end{array}$ & CBS 2517 & kaaf_1 & YGOB & YGOB & 2 \\
\hline & & $\begin{array}{l}\text { Kazachstania } \\
\text { naganishii }\end{array}$ & CBS 8797 & kana_1 & YGOB & YGOB & 2 \\
\hline & \multirow[t]{3}{*}{ Naumovozyma } & \multirow{2}{*}{$\begin{array}{l}\text { Naumovozyma } \\
\text { castellii }\end{array}$} & CBS 4309 & naca_1 & YGOB & YGOB & 2 \\
\hline & & & NRRL Y-12630 & naca_2 & $S G D$ & YGAP & 2 \\
\hline & & $\begin{array}{l}\text { Naumovozyma } \\
\text { dairenensis }\end{array}$ & CBS 421 & nada_1 & YGOB & YGOB & 2 \\
\hline & \multirow[t]{2}{*}{ Nakaseomyces } & \multirow[t]{2}{*}{ Candida glabrata } & CBS138 & cagl_1 & YGOB & YGOB & 2 \\
\hline & & & ССТCC M202019 & cagl_2 & Genbank & YGAP & 2 \\
\hline & \multirow[t]{2}{*}{ Tetrapisispora } & $\begin{array}{l}\text { Tetrapisispora } \\
\text { phaffii }\end{array}$ & CBS 4417 & teph_1 & YGOB & YGOB & 2 \\
\hline & & $\begin{array}{l}\text { Tetrapisispora } \\
\text { blattae }\end{array}$ & CBS 6284 & tebl_1 & YGOB & YGOB & 1 \\
\hline & Vanderwaltozyma & $\begin{array}{l}\text { Vanderwaltozyma } \\
\text { polyspora }\end{array}$ & DSM 70294 & vapo_1 & YGOB & YGOB & 2 \\
\hline \multirow[t]{11}{*}{ Pre-WGD } & \multirow[t]{3}{*}{ Zygosaccharomyces } & \multirow{2}{*}{$\begin{array}{l}\text { Zygosaccharomyces } \\
\text { bailii }\end{array}$} & IST302 & zbist & UD & UD & 1 \\
\hline & & & CLIB $213^{\top}$ & zyba_3 & Genbank & YGAP & 1 \\
\hline & & $\begin{array}{l}\text { Zygosaccharomyces } \\
\text { rouxii }\end{array}$ & CBS 732 & zyro_1 & YGOB & YGOB & 1 \\
\hline & Torulaspora & $\begin{array}{l}\text { Torulaspora } \\
\text { delbrueckii }\end{array}$ & CBS 1146 & tode_1 & YGOB & YGOB & 1 \\
\hline & \multirow[t]{3}{*}{ Lachancea } & Lachancea kluyvery & CBS 3082 & lakl_1 & YGOB & YGOB & 1 \\
\hline & & $\begin{array}{l}\text { Lachancea } \\
\text { thermotolerans }\end{array}$ & CBS 6340 & lath_1 & YGOB & YGOB & 1 \\
\hline & & Lachancea waltii & NCYC 2644 & lawa_1 & YGOB & YGOB & 1 \\
\hline & \multirow[t]{4}{*}{ Kluyveromyces } & $\begin{array}{l}\text { Kluyveromyces } \\
\text { lactis }\end{array}$ & CLIB210 & klla_1 & YGOB & YGOB & 1 \\
\hline & & $\begin{array}{l}\text { Kluyveromyces } \\
\text { marxianus var. } \\
\text { Marxianus }\end{array}$ & KCTC 17555 & klma_1 & Genbank & YGAP & 1 \\
\hline & & $\begin{array}{l}\text { Kluyveromyces } \\
\text { wickerhamii }\end{array}$ & UCD 54-210 & klwi_1 & Genbank & YGAP & 1 \\
\hline & & $\begin{array}{l}\text { Kluyveromyces } \\
\text { aestuarii }\end{array}$ & ATCC 18862 & klae_1 & Genbank & YGAP & 1 \\
\hline
\end{tabular}


Table 1 Saccharomycetaceae yeast strains examined in this work (Continued)

\begin{tabular}{lllllll}
\hline Eremothecium & Eremothecium & ATCC 10895 & ergo_1 & YGOB & YGOB & 1 \\
& gossypii & & & & \\
& Eremothecium & DBVPG 7215 & ercy_1 & YGOB & YGOB & 1 \\
& cymbalariae & & & & & \\
& Ashbya aceri & - & asac_1 & Genbank YGAP & 1 \\
\hline
\end{tabular}

SGD Saccharomyces Genome Database (http://www.yeastgenome.org/download-data/sequence), Genbank (http://www.ncbi.nlm.nih.gov/genome/browse/); Sanger (http://www.sanger.ac.uk/research/projects/genomeinformatics/sgrp.html), YGOB Yeast Gene Order Browser (http://ygob.ucd.ie/), YGAP Yeast Genome Annotation Pipeline (http://wolfe.ucd.ie/annotation/), UD unpublished data (Palma M. et al.: Genome sequence of the highly weak-acid-tolerant Zygosaccharomyces bailii IST302, amenable to genetic and physiological manipulations, unpublished)

sequenced yeast strains. This required the compilation and organization of a total of 199443 translated ORFs. These translated ORFs were organized into a blast database and compared all-against-all using blastp algorithm made available in blast2 package [31]. The blastp algorithm used a gapped alignment with the following parameters: open gap $(-1)$, extend gap $(-1)$, threshold for extending hits (11) and word size (3). This approach generated a total of 45.5 million pairwise alignments. In order to handle this amount of data, sequence clustering was formulated as a graph traversal problem, where the nodes are the translated ORFs and the edges indicate the existence of pairwise sequence similarity between amino acid sequences. Classification of the translated ORFs into clusters was achieved by breadth-first traversing this network at different e-value thresholds, ranging from E-60 to E-1. The identification of the putative Haa1/Cup2 homologues was achieved by traversing these blastp sub-networks using as starting node the $S$. cerevisiae Haal protein.

\section{Phylogenetic analysis and tree construction methods}

The amino acid sequences of the gathered translated ORFs were used to build a multiple alignment using MUSCLE software [32]. This multiple alignment was analysed using the Jalview software [33] and processed using the MrBayes [34, 35], a Bayesian Markov chain Monte Carlo (MCMC) package for phylogenetic analysis. The functions made available in the seqinr and ape $R$ packages [36] were used to convert the multiple alignment in fasta format into a nexus file required as input by MrBayes. Metropolis coupling of the MCMC sampling of the target distribution made available by the MPI (Message Passing Interface) version of MrBayes was used to speed up phylogeny computation. MrBayes MPI was set to use one "cold" chain together with 9 heated chains, while the remaining MPI parameters were set to default values. The MCMC simulations used 1200000 generations and two independent runs (each started from two distinct random trees) to confirm parameter convergence of the posterior probability distribution and, hence, assuring convergence into similar phylogenetic trees. The option of estimating the fixedrate amino acid model made available by MrBayes was used, allowing the MCMC sampler to explore all of the nine available models by regularly proposing new ones (upon parameter convergence, each model contributes to the results in proportion to its posterior probability) and rate variation over sites was assumed to follow a gamma distribution. The maximum likelihood PROTML algorithm made available by the PHYLIP package coupled with bootstrap sampling [37] was used to confirm the results obtained with the MrBayes software suite (Additional file 4). The Dendroscope software was used for tree visualization [38].

\section{Gene neighbourhood analysis}

The package "sqldf" [39] and complementing scripting in R language was used to retrieve fifteen neighbour genes on each side of the query genes as well as the corresponding sequence clustering classification from Genome DB. The rationale of synteny analysis was described before [40, 41].

The existence of synteny between query genes was verified through the analysis of network topology (number of shared neighbour pairs) and the biological information associated with the corresponding edges. Three sources of biological information were used to assess the strength of each neighbour pair connection [40]: i) closeness of the connecting neighbours in relation to the query genes, ii) sequence similarity between connecting neighbours and iii) dimension of the sequence cluster to which the homologous neighbours belong; small dimension of the sequence cluster indicates that it is small the probability that two homologous neighbours are in the vicinity of two query genes by chance.

\section{Results}

Identification of S. cerevisiae Haa1 homologues in Z. bailii and in other Saccharomycetaceae yeast species

The Haa1 protein from S. cerevisiae S288c was selected as the starting node for the traversal of the blastp network. The iterative constraining and traversing of this pairwise similarity network at different e-values allowed the identification of the homologues of Haal transcription factor encoded in the genome sequences of $Z$. bailii CLIB $213^{\mathrm{T}}$ and IST302 and in other 31 Saccharomycetaceae strains (corresponding to a total of 28 species) (Table 1). The plot representing the number of sequences retrieved at different e-values shows four distinct blastp clustering ranges (Fig. 1). The first range 


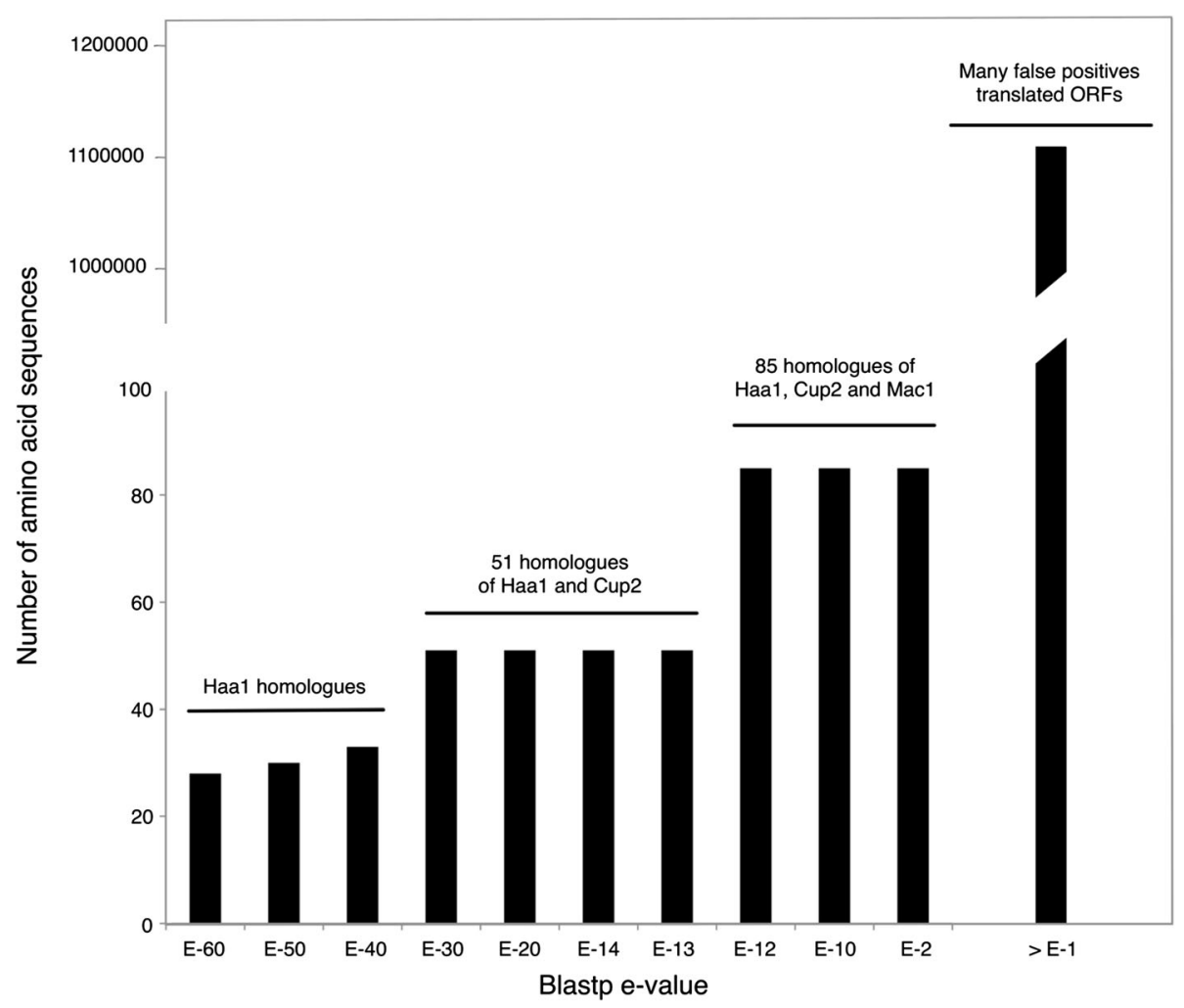

Fig. 1 Number of sequences retrieved after constraining and traversing the pairwise similarity network at different e-values using the Haa1 sequence from S. cerevisiae S288c as 'starting node'. This analysis retrieved three successive protein sequence plateaus, depending on the e-value threshold applied, corresponding to the homologues of the S. cerevisiae Haa1, Cup2 and Mac1 proteins. An e-value of E-13 was chosen to constrain the pairwise similarity network and 51 amino acid sequences of Haa1 and Cup2 homologues were retained for further evolutionary analyses

occurs between e-values E-60 to E-40, gathering amino acid sequences highly similar to the starting node Haa1. In the second blastp clustering range (e-values from E30 to E-13), the amino acid sequences similar to $S$. cerevisiae Cup2 protein are merged with the Haa1 protein set into a single group comprising a total of 51 sequences. In the third blastp clustering range (e-values from E-12 to E-2), the homologues of the S. cerevisiae Mac1 transcription factor are merged with the Haa1/ Cup2 protein set (a total of 87 amino acid sequences). In the fourth blastp clustering range (e-values bellow E-1) many false positive amino acid sequences were incorporated in the Haa1/Cup2/Mac1 protein set. The cause for the merge of the Mac1 protein set with the Haa1/Cup2 homologues at low blastp e-values is the sharing of copper fist domain in the N-terminal of all these $S$. cerevisiae transcription factors. Considering that Mac1 is remotely similar to the Haa1 and Cup2 proteins, an evalue of E-13 was selected to constrain the pairwise similarity network and the corresponding 51 amino acid sequences were retained for further analysis (Additional file 3). The joint retrieval from the blastp network of both $S$. cerevisiae Haa1 and Cup2 transcription factors support the previous suggestion that the encoding genes constitute a paralogue pair $[1,19,20]$ and allowed to conclude that the genome sequences of the two Z. bailii strains scrutinized in this study encode a single Haal homologue (Table 1) that is also homologous to Cup2. Consistent with the joint retrieval of Haa1 and Cup2 homologues, that in $S$. cerevisiae correspond to two independent transcription factors with 694 and 225 amino acids, respectively, the amino acid sequences herein identified in 28 Saccharomycetaceae species comprise highly heterogeneous protein sizes. Similar to the $S$. cerevisiae Haa1 (ScHaa1), Z. bailii sole Haa1/Cup2 homologue (ZbHaa1) has a protein size of 694 amino acid residues.

Expression of the HAA1 homologue from Z. bailii leads to increased tolerance of $S$. cerevisiae to acetic acid

To investigate the suggested role of the HAA1 homologues from two $Z$. bailii strains in acetic acid tolerance, the susceptibility to acetic acid of $S$. cerevisiae BY4741 and derived deletion mutant haa1s strains expressing either $Z b H A A 1$ or $S c H A A 1$ was compared (Fig. 2). Two ZbHAA1 gene alleles were considered in this analysis, one from Z. bailii IST302 (ORF ZBIST_2620, Additional 
a S. cerevisiae BY4741

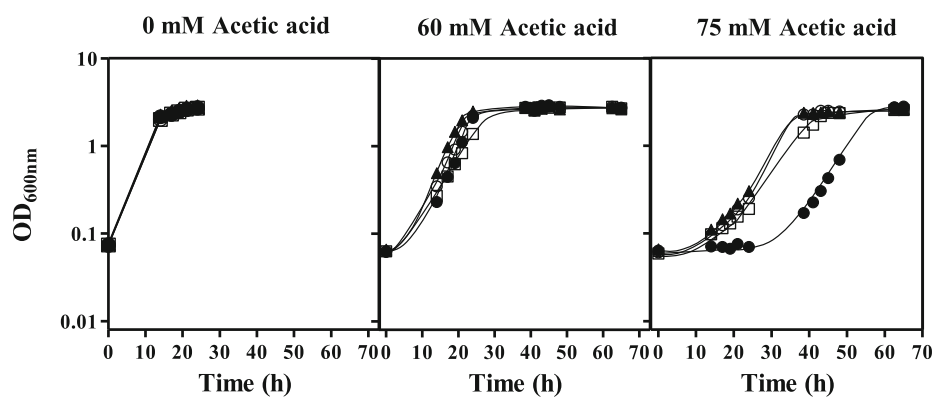

b S. cerevisiae BY4741_haa1s

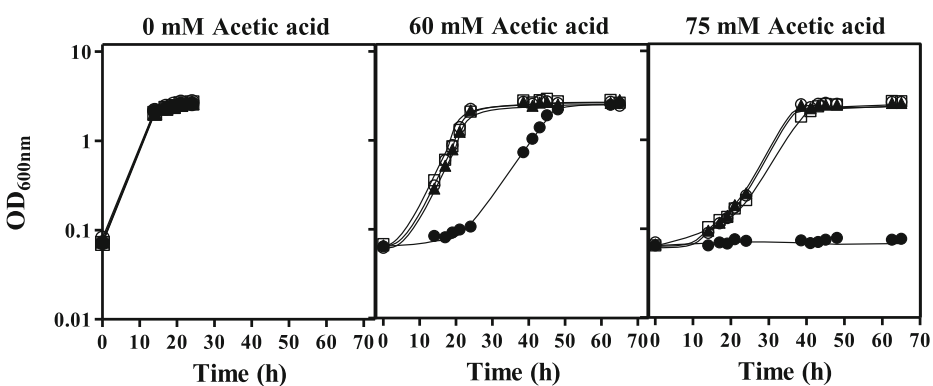

Fig. 2 Expression of HAA1 homologues of Z. bailii IST302 and CLIB $213^{\top}$ or S. cerevisiae BY4741 from SCHAA1 natural promoter increases acetic acid tolerance of $S$. cerevisiae BY4741 and derived deletion mutant haal $\triangle$. Growth curves of a S. cerevisiae BY4741 and $\mathbf{b}$ S. cerevisiae BY4741 haa1 $\triangle$ mutant strain expressing the cloning vector pGREG506_noHIS3 $(\bullet)$ or the recombinant plasmids pG_ZbHAA1-IST $(\mathbf{\Delta})$, pG_ZbHAA1-CL (o) and pG_ScHAA1 (口), in MM4 medium ( $\mathrm{pH}$ 4.0) without uracil (to keep selective pressure over the recombinant strains), supplemented with 0, 60 or $75 \mathrm{mM}$ of acetic acid. The growth curves are representative of at least three independent growth assays that produced similar results

file 2 (Palma $M$ et al.: Genome sequence of the highly weak-acid-tolerant Zygosaccharomyces bailii IST302, amenable to genetic and physiological manipulations, unpublished) and the other from $Z$. bailii CLIB $213^{\mathrm{T}}$ [22]. Both nucleotide sequences share $99.7 \%$ identity, with the corresponding encoded proteins having three amino acid substitutions. These $Z b H A A 1$ genes were cloned into pGREG506 under the control of $S$. cerevisiae BY4741 $H A A 1$ promoter. S. cerevisiae BY4741 HAA1 gene sequence was also cloned into the same vector, under the control of its native promoter and used as an internal control for comparative expression experiments. The expression of either ScHAA1 or the two ZbHAA1 genes in S. cerevisiae BY4741, cultivated in supplemented media with 60 or $75 \mathrm{mM}$ acetic acid, significantly reduced the duration of the latency phases and increased the specific growth rates when compared with the host strain harbouring the cloning vector (Fig. 2a, Table 2). Interestingly, the increase of acetic acid tolerance of $S$. cerevisiae parental strain was maximal when $Z b H A A 1$ from the more tolerant yeast strain Z. bailii IST302 (Palma $M$ et al.: Genome sequence of the highly weak-acid-tolerant Zygosaccharomyces bailii IST302, amenable to genetic and physiological manipulations, unpublished) was expressed (Table 2). Also, the heterologous expression of $Z b H A A 1$ gene alleles in haa1 $\Delta$ mutant strain was found to rescue the susceptibility phenotype of the deletion mutant by increasing its tolerance to $60 \mathrm{mM}$ acetic acid up to the level of the haa1 $\triangle$ mutant expressing ScHAA1 gene (the duration of the latency phase is reduced of approximately $30 \mathrm{~h}$ ) (Fig. 2b; Table 2). Differences registered in acetic acid tolerance in the parental strain harbouring the cloning vector and in the haa1D mutant expressing ScHAA1 (Fig. 2; Table 2) are likely the result of $S c H A A 1$ expression from a centromeric vector [24] and not from the chromosomal locus. In fact, the mRNA levels from ScHAA1 in haalD expressing ScHAA1 from the recombinant vector are above those in the parental strain transformed with the cloning vector, both in the absence (Time point 0 ) or presence of acetic acid stress (Time points 1 and 2) (Fig. 3a). However, the mRNA levels from $Z b H A A 1$ in haa1 $\triangle$ expressing $Z b H A A 1$ could not be calculated because the parental strain used as a reference strain for the calculation of relative mRNA levels does not harbour the $Z b H A A 1$ gene (Fig. 3b).

ZbHaa1 is involved in the regulation of $\mathrm{S}$. cerevisiae acetic acid-responsive gene $Y G P 1$

The mRNA levels from YGP1 gene in $S$. cerevisiae, whose transcriptional activation under acetic acid stress is dependent on Haa1 [4], were compared in S. cerevisiae haa1D mutant expressing either ScHAA1 or ZbHAA1 
Table 2 Duration of the lag phase of growth (h) and maximum specific growth rates $\left(\mu_{\max }\left(\mathrm{h}^{-1}\right)\right)$

\begin{tabular}{|c|c|c|c|c|c|c|}
\hline \multirow[b]{2}{*}{ Strain } & \multicolumn{2}{|c|}{$0 \mathrm{mM}$ Acetic acid } & \multicolumn{2}{|c|}{$60 \mathrm{mM}$ Acetic acid } & \multicolumn{2}{|c|}{$75 \mathrm{mM}$ Acetic acid } \\
\hline & Lag phase (h) & $\mu_{\max }\left(h^{-1}\right)$ & Lag phase (h) & $\mu_{\max }\left(h^{-1}\right)$ & Lag phase (h) & $\mu_{\max }\left(h^{-1}\right)$ \\
\hline BY4741 + pGREG506_noHIS3 & - & $0.22 \pm 0.016$ & $12.7 \pm 3.4$ & $0.22 \pm 0.007$ & $35.6 \pm 5.4$ & $0.15 \pm 0.010$ \\
\hline BY4741 + pG_ScHAA1 & - & $0.22 \pm 0.013$ & $8.3 \pm 2.2$ & $0.16 \pm 0.004$ & $15.4 \pm 1.8$ & $0.12 \pm 0.004$ \\
\hline $\mathrm{BY} 4741+$ pG_ZbHAA1-CL & - & $0.21 \pm 0.023$ & $7.2 \pm 2.1$ & $0.20 \pm 0.010$ & $11.9 \pm 1.0$ & $0.13 \pm 0.002$ \\
\hline BY4741 + pG_ZbHAA1-IST & - & $0.23 \pm 0.016$ & $6.3 \pm 2.3$ & $0.21 \pm 0.018$ & $10.8 \pm 0.4$ & $0.13 \pm 0.001$ \\
\hline haa1D + pGREG506_noHIS3 & - & $0.23 \pm 0021$ & $37.1 \pm 5.0$ & $0.16 \pm 0014$ & NG & NG \\
\hline haal $\Delta+$ pG_ScHAA1 & - & $0.23 \pm 0014$ & $7.9 \pm 1.2$ & $0.18 \pm 0013$ & $15.5 \pm 1.9$ & $0.13 \pm 0002$ \\
\hline haa1 $\triangle+$ pG_ZbHAA1-CL & - & $0.23 \pm 0013$ & $8.1 \pm 0.9$ & $0.21 \pm 0010$ & $14.3 \pm 0.0$ & $0.15 \pm 0001$ \\
\hline haal + pG_ZbHAA1-IST & - & $0.24 \pm 0015$ & $9.1 \pm 1.2$ & $0.19 \pm 0017$ & $12.9 \pm 0.7$ & $0.14 \pm 0005$ \\
\hline
\end{tabular}

Duration of the lag phase of growth $(\mathrm{h})$ induced by acetic acid stress and maximum specific growth rates $\left(\mu \mathrm{max}\left(\mathrm{h}^{-1}\right)\right)$ of $S$. cerevisiae BY4741 and derived deletion mutant haa1A expressing ZbHAA1 from Z. bailii strains IST302 (pG_ZbHAA1-IST) and CLIB 213 (pG_ZbHAA1-CL), S. cerevisiae HAA1 (pG_ScHAA1) or the cloning vector (pGREG506_noHIS3). Mean and standard deviation values of at least three independent experiments are indicated. (-) No lag phase detected; (NG) No growth detected during the course of the experiment $(65 \mathrm{~h})$

and in the parental strain and derived haa1s mutant transformed with the cloning vector (Fig. 3c). As expected, the relative mRNA levels from YGP1 gene in the haa1 $\Delta$ mutant were below the levels in the parental strain, both in the absence of acetic acid (Time point 0 ) or following sudden exposure to acetic acid (Time points 1 and 2). An increase in mRNA levels from $Y G P 1$ gene was detected in the haa1 $\triangle$ mutant expressing $Z b H A A 1$ or ScHAA1, respectively after 1 and $2 \mathrm{~h}$ of acetic acid supplementation of the growth medium, but no activation was detected in haals harbouring the cloning vector (Fig. 3c). These results indicate that $\mathrm{ZbHaa1}$ is also able to mediate the transcriptional activation of YGP1 in $S$. cerevisiae cells challenged with acetic acid stress.

\section{$Z b H A A 1$ is required for $Z$. bailii tolerance to several weak acids}

To examine the hypothesized role of the expression of ZbHAA1 in Z. bailii tolerance to acetic acid, a Zbhaa1A deletion mutant was prepared in Z. bailii IST302 and the susceptibility of the parental strain and derived mutant to acetic acid, as well as to other weak acids used
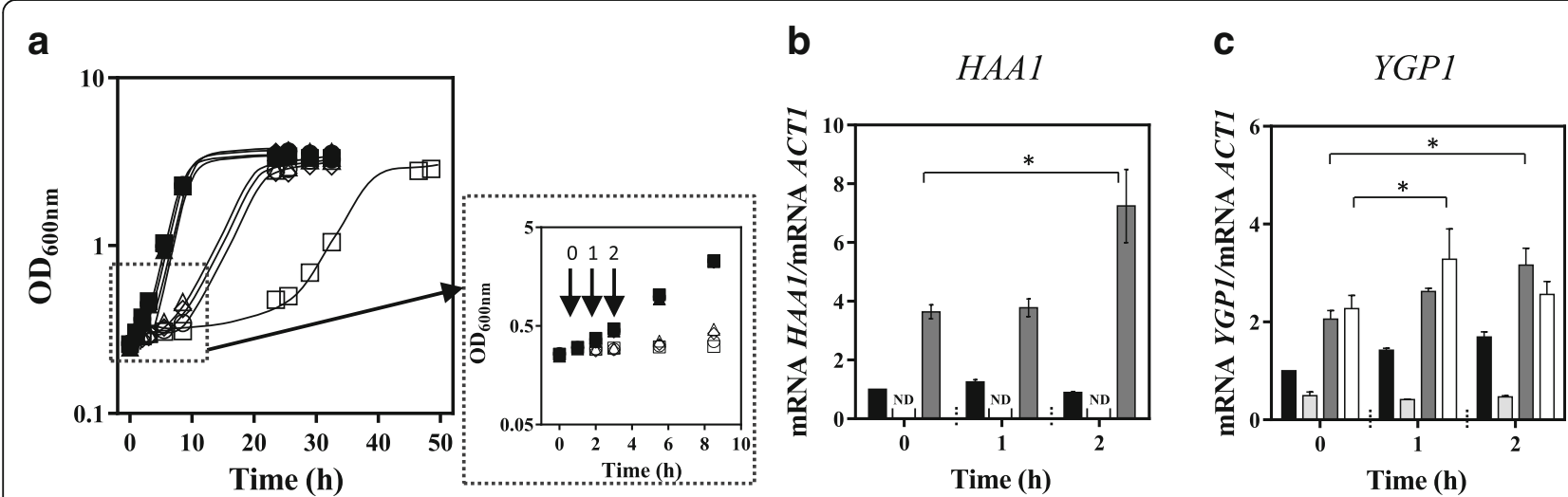

Fig. 3 Like ScHaa1, ZbHaa1 is able to mediate the transcriptional activation of YGP1 in S. cerevisiae under acetic acid stress. The effect that the expression of ZbHAA1 or SCHAA1 in S. cerevisiae haa1 $\triangle$ has in the transcript levels from the ScHaa1 target gene YGP1 was compared. a Growth curves of S. cerevisiae BY4741 parental strain transformed with the cloning vector $(\bullet, 0)$ and of its derived deletion mutant haa $\triangle \triangle$ expressing the recombinant plasmids pG_ZbHAA1-IST $(\bullet, \diamond)$, pG_ScHAA1 $(\boldsymbol{\Delta}, \Delta)$ or the cloning vector $(\mathbf{\bullet}, \square)$ cultivated in MM4-U (filled symbols) or in the same medium supplemented with acetic acid (empty symbols). Yeast cells were harvested before acetic acid supplementation (Time point 0), or 1 or $2 \mathrm{~h}$ after acetic acid addition (Time points 1 and 2, respectively). b Transcript levels from HAA1 in S. cerevisiae BY4741 transformed with the cloning vector (black bar), in S. cerevisiae deletion mutant haal $\triangle$ transformed with the cloning vector (ND-not detected), or expressing ScHAA1 (dark grey bar). c Transcript levels from YGP1 in S. cerevisiae BY4741 transformed with the cloning vector (black bar), in S. cerevisiae deletion mutant haa $1 \triangle$ transformed with the cloning vector (light grey bar), or expressing SCHAA1 (dark grey bar) or ZbHAA1 (white bar). ACT1 mRNA level was used as an internal control. The mRNA levels from HAA1 and YGP1 genes in S. cerevisiae BY4741 transformed with the cloning vector in the absence of acetic acid (Time point 0) were set as 1 and the transcript levels from those genes were calculated relative to this control. mRNA values shown are the mean of, at least, three independent experiments. Results were analysed by two-way ANOVA. ${ }^{*}$ ) $p$-value below 0.05 , when comparing the relative mRNA levels in each strain at a given time point 
as food preservatives (benzoic and sorbic acids), was compared by spot assays (Fig. 4a). Using equivalent concentrations of the different weak acids or, in other words, concentrations that induce a similar duration of growth latency of the parental strain, it was possible to demonstrate that $Z b H A A 1$ expression is required for increased $Z$. bailii tolerance to the three weak acid food preservatives tested, but $Z b H A A 1$ protective effect was more evident under acetic acid stress (Fig. 4a). In fact, no cell growth was detected in the Zbhaa1S mutant strain after 4 days of incubation with $220 \mathrm{mM}$ acetic acid, whereas this mutant strain was still able to resume growth after a latency of approximately 4 days when cultivated in the presence of equivalent concentrations of the more lipophilic benzoic and sorbic acids. This result is in line with results reported before for the effect of HAA1 in S. cerevisiae indicating that maximal protection is exerted against the short-chain length more hydrophilic weak acids [2].

Weak acid concentrations that impaired growth of $Z$. bailii IST302 harbouring the cloning vector were used to compare the tolerance of $Z$. bailii IST302 expressing an extra copy of ZbHAA1 (Fig. 4b) that led to a remarkable increase of $Z$. bailii tolerance to the three weak acids (Fig. 4b). The enhanced tolerance to acetic acid of Z. bailii IST302 expressing an extra copy of ZbHAA1 was also confirmed in liquid MM medium supplemented with $220 \mathrm{mM}$ acetic acid at $\mathrm{pH} 4.0$, where a decreased

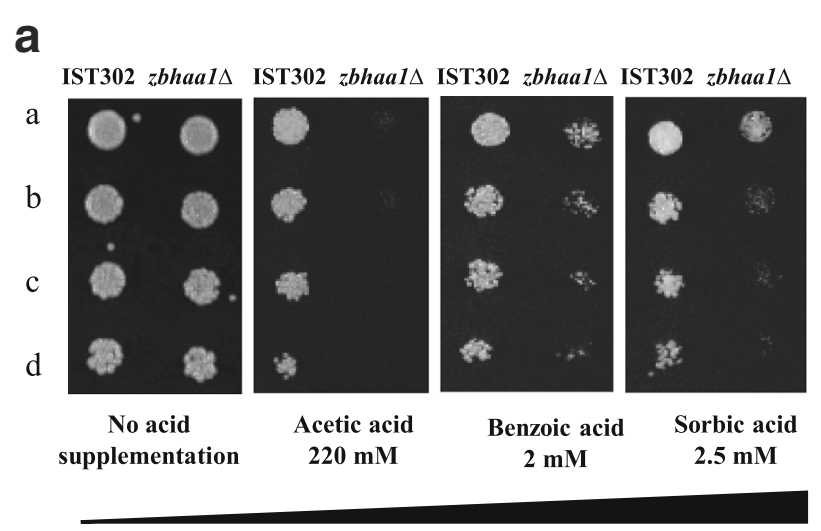

Lipophilicity

\section{b}

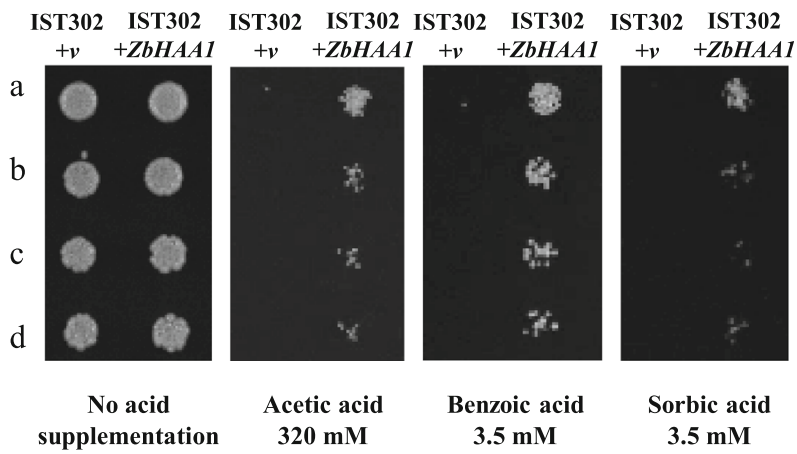

C

$0 \mathrm{mM}$ Acetic acid $\quad 180 \mathrm{mM}$ Acetic acid $\quad 220 \mathrm{mM}$ Acetic acid

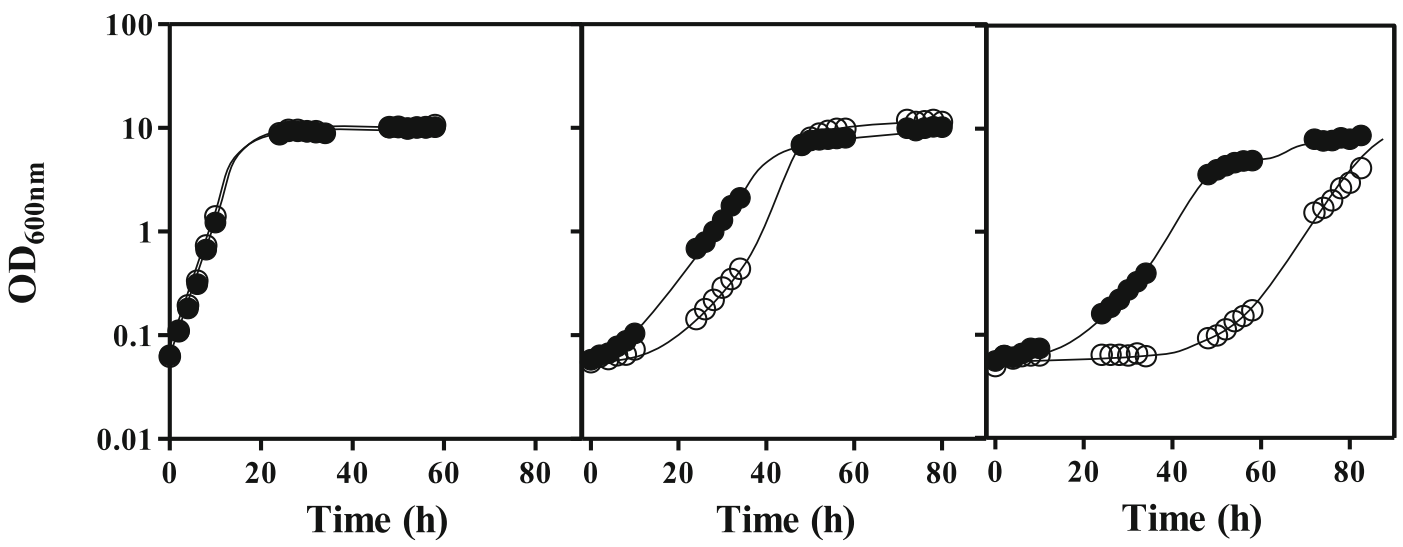

Fig. 4 The ZbHAA1 is a determinant of tolerance to acetic acid in Z. bailii. a Growth of Z. bailii IST302 and derived mutant Zbhaa1 $\triangle$ was compared by spot assays in MM medium ( $\mathrm{pH}$ 4.5) supplemented, or not, with equivalent concentrations of acetic, benzoic and sorbic acids (i.e. concentrations that induced similar growth inhibition in strain IST302). b Growth of Z. bailii IST302 harbouring the cloning vector $\mathrm{pZ} Z_{3} b T(+\mathrm{v})$ and $Z$. bailii IST302 expressing an extra copy of ZbHAA1 (+ZbHAA1) was compared by spot assays in MM medium ( $\mathrm{pH}$ 4.5) supplemented, or not, with concentrations of the different weak acids that impaired growth of Z. bailii IST302 (+v). The images depicted in $\mathbf{a}$ ) and $\mathbf{b}$ ) were taken, respectively, after 4 or 5 days of incubation at $30{ }^{\circ} \mathrm{C}$ and are representative of at least three independent experiments. For both a) and b), cell suspensions with an absorbance at $600 \mathrm{~nm}$ of $0.05 \pm 0.005$ (lane a) and subsequent dilutions of 1:5, 1:10 and 1:20 (lanes b, c and d, respectively) were spotted onto the surface of agarized medium; c Growth curves of Z. bailii IST302 expressing an extra copy of ZbHAA1 ( $\bullet$ ) or harbouring the cloning vector $\mathrm{pZ}_{3} \mathrm{bT}$ ( (0). Growth was performed in MM medium (pH 4.0) supplemented with 0, 180 or 220 mM acetic acid. Growth curves are representative of at least three independent growth assays that produced similar results 
duration of the latency phase of approximately $30 \mathrm{~h}$ was observed (Fig. 4c). In summary, ZbHAA1 is an important player in $Z$. bailii tolerance to acetic acid and other weak acid food preservatives.

\section{ZbHaa1 is required for acetic acid-induced transcriptional activation of $Z$. bailii genes homologous to $S$. cerevisiae Haa1-target genes}

The effect of the presence of acetic acid stress and the expression of ZbHAA1 in the transcription levels from six $Z$. bailii genes homologous to $S$. cerevisiae genes whose transcription was previously reported to be dependent on Haal regulation under acetic acid stress [4], was examined (Fig. 5). The nucleotide sequences of the referred $Z$. bailii genes, homologous to $S$. cerevisiae Haal target genes, specifically ZbHRK1, ZbHSP30, ZbTPO3, ZbMSN4, ZbYGP1 and ZbYRO2, are available in Additional file 2. The mRNA levels from the selected putative ZbHaal targets in Z. bailii IST302 were found to increase during the early adaptive response to the acid, specifically $1 \mathrm{~h}$ after sudden exposure to acetic acid, this activation being significantly reduced in Zbhaa1s deletion mutant (Fig. 5). These results indicate that the activation of the selected genes in response to acetic acid a

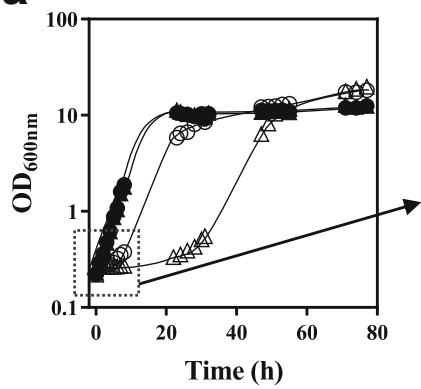

C
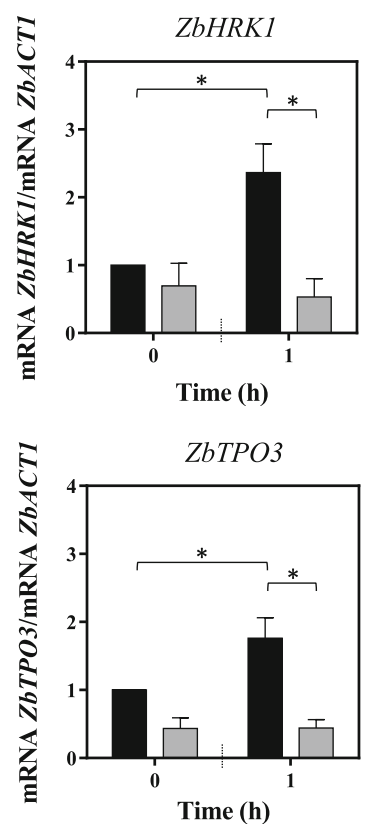
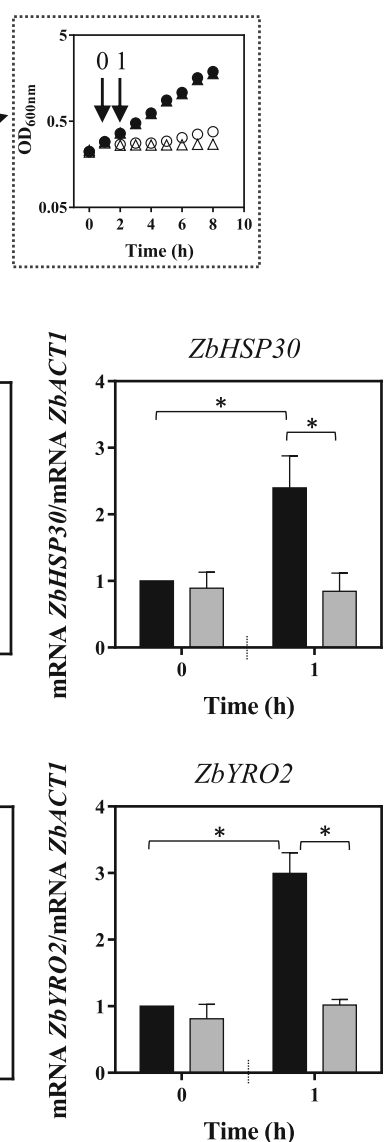

b
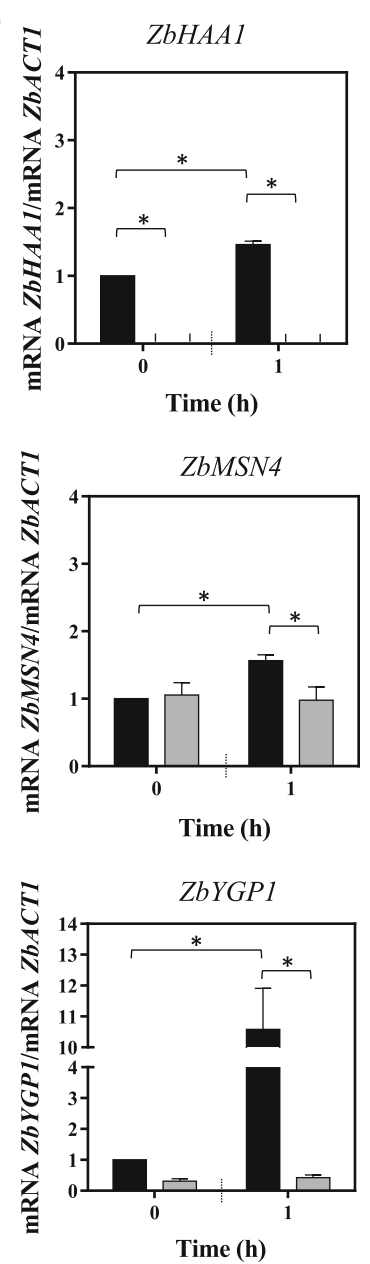

Fig. $5 \mathrm{ZbHaa} 1$ is required for acetic acid induced transcriptional activation of $Z$. bailii genes demonstrated to be homologous to $S$. cerevisiae Haa1 target genes. a Growth curves of Z. bailii IST302 $(\bullet, 0)$ and of its derived deletion mutant Zbhaa1 $\Delta(\boldsymbol{\Lambda}, \Delta)$ cultivated in MM medium, $\mathrm{pH} 4.0$ (filled symbols) or in the same medium supplemented with acetic acid (empty symbols). Acetic acid was added after $1 \mathrm{~h}$ of growth of exponential cells prepared under standard conditions in MM medium to a final concentration of $140 \mathrm{mM}$. Yeast cells were harvested before acetic acid supplementation (Time point 0) and $1 \mathrm{~h}$ after acetic acid addition (Time point 1). Comparison of the transcript levels from $\mathbf{b} Z$ ZbHAA1,

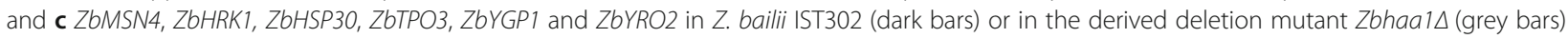
in the absence of acetic acid (Time point 0 ) and $1 \mathrm{~h}$ after acetic acid supplementation (Time point 1). ZbACT1 mRNA level was used as an internal control. The mRNA level from Z. bailii IST302 genes ZbHAA1, ZbMSN4, ZbHRK1, ZbHSP3O, ZbTPO3, ZbYGP1 and ZbYRO2 in the absence of acetic acid (Time point 0 ) were set as 1 and the transcript levels from those genes were calculated relative to this control. mRNA values shown are the mean of, at least, three independent experiments. Results were analysed by two-way ANOVA. ${ }^{*}$ ) $p$-value below 0.05 , when comparing the relative mRNA levels in each strain at a given time point 
stress is dependent on ZbHaal, and suggest that the Haal regulon is similar in $S$. cerevisiae and $Z$. bailii species.

\section{Phylogenetic analysis of the Haa1 and Cup2 homologues in Saccharomycetaceae yeasts}

Using the multiple alignment of the amino acid sequences of the putative Haa1 and Cup2 homologues of 33 strains from 28 pre- and post- WGD species, including Z. bailii CLIB $213^{\mathrm{T}}$ and IST302 sequences, as input, MrBayes phylogenetic software suite was used to construct a phylogenetic tree representing this family of transcription factors with copper-fist binding domain. After running two MCMC simulations for 1200000 generations, the standard deviation of split frequencies was below 0.01 and the potential scale reduction factor (PSRF) was reasonably close to 1.0 for all parameters, indicating their convergence $[42,43]$. The parameters of the Gamma distribution, assumed being equal by MrBayes, converged into a value of 1.145, with the 95\% Highest Posterior Density (HPD) interval ranging from 1.037 to 1.262 , while the total tree length of the phylogenetic tree converged into a value of 37.112 (95\% HPD interval = 34.139-40.085). The corresponding consensus Bayesian phylogenetic tree was retained for further analysis. A maximum likelihood (ML) approach made available by the PhyML software suite was used to confirm the phylogenetic relationships between the Haa1 and Cup2 homologues. The credibility of the phylogenetic clades was confirmed by inspection of the bipartition probabilities and bootstrapping values calculated for each internal node of the Bayesian and ML trees, respectively. Since the Bayesian and the ML statistical approaches originated similar phylogenetic trees regarding cluster composition and credibility (Fig. 6, Additional file 4), the analysis of the phylogenetic relationships between these transcription factors made in this study is based only in the tree obtained with MrBayes.

The analysis of the multiple alignment of the Haa1 and Cup2 transcription factor homologues revealed that their transactivation domain is poorly conserved in the Saccharomycetaceae yeast species under study, being responsible for the long branches observed in the corresponding tree (Fig. 6). This phylogenetic tree is divided into eight clusters, labelled from $\mathrm{A}$ to $\mathrm{H}$. The translated ORF teph_1_d00690 was chosen as outgroup of this phylogenetic tree (cluster A) due to the strong dissimilarity of its amino acid sequence when compared with the ones of the remaining members of this gene family. The division of the Haa1 and Cup2 homologues into the proposed phylogenetic clusters was based on the following criteria: 1) protein length and 2) the taxonomic classification of the yeast species encoding each putative transcription factor. Cluster $\mathrm{H}$ comprises only proteins ranging from 221 to 356 amino acids (260 amino acids in average) and the remaining clusters comprise proteins ranging from 525 to 893 amino acids (671 amino acids in average). Nevertheless, the analysis of the amino acid and nucleotide sequences confirmed that all the phylogenetic clusters comprise full-size proteins, being free of fragments, pseudogenes and other type of sequence artefacts. The protein size and the analysis of the amino acid sequence similarity relationships shown by these transcription factors suggests that cluster $\mathrm{H}$ comprises the orthologues of S. cerevisiae Cup2 and clusters A, B, C, D and G comprise the orthologues of S. cerevisiae Haa1. With the exception of Tetrapisispora blattae, the genomes of the yeast species that have diverged after the WGD event encode two proteins belonging to this gene family, each one corresponding to the Haa1 or the Cup2 orthologues. Reinforcing the notion that these two $S$. cerevisiae genes are paralogues with origin in the WGD event $[1,19,20]$ is the fact that the genomes of the protoploid Saccharomycetaceae species analysed in this study encode a single Haa1/Cup2 homologue (clusters E and F). Consistently, the genomes of the yeast species classified in the Zygosaccharomyces taxonomic genus under analysis in this study encode a single Haa1/Cup2 homologue: Z. bailii IST302 (ZBIST_2620), Z. bailii CLIB $213^{\mathrm{T}}$ (ZYBA_3_9_I00670) and $Z$. rouxii CBS 732 (ZYRO_1_F04862g).

All-against-all Needleman-Wunsch alignments were constructed to cross-compare the amino acid sequence similarity between the possible combinations of these three groups of proteins: Haal orthologues (clusters A, B, C, D and G), Cup2 orthologues (cluster $\mathrm{H}$ ) and Haa1/Cup2 orthologues encoded in the protoploid Saccharomycetaceae genomes (clusters E and F). The amino acid sequence of the Haal and Cup2 orthologues showed, in average, $29.7 \%$ and $15.0 \%$ identity with Haa1/Cup2 protoploid orthologues, respectively (with the pairwise alignment comprising $63.5 \%$ and $31.7 \%$ of gaps, respectively). On the other hand, the comparison between the Haal orthologues versus the Cup2 orthologues showed that these share, in average, $12.7 \%$ identity between the corresponding amino acid sequences (and $67.4 \%$ of gaps). Considering that the protein size of the postWGD Cup2 orthologues is less than one half of the size shown by the post-WGD Haal orthologues and of the protoploid Haa1/Cup2 orthologues, it is likely that the lower sequence identity between Cup2 orthologues and the members of other phylogenetic clusters is essentially due to the heterogeneous size and gap introduction in the pairwise sequence alignments. 


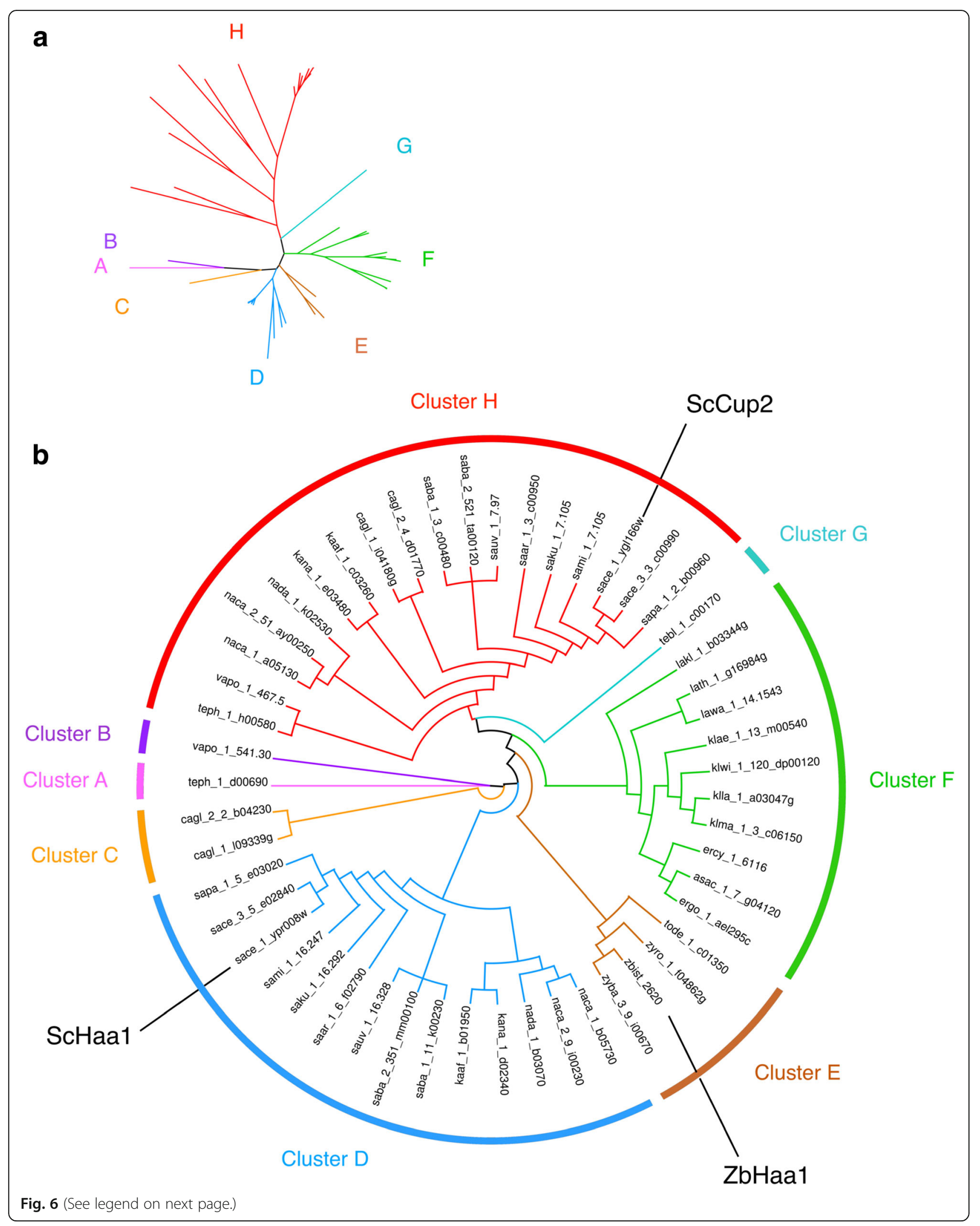


(See figure on previous page.)

Fig. 6 Phylogenetic analysis of S. cerevisiae Haa1 and Cup2 transcription factors homologues encoded in the genomes of 33 strains of 28 yeast species belonging to the Saccharomycetaceae family. a Radial phylogram showing the amino acid sequence similarity distances between these 51 full-size proteins. b Circular cladogram showing the tree topology, with the name of the S. cerevisiae and Z. bailii members indicated. MrBayes software suite was used in phylogenetic tree calculation using simulation statistical options described in materials and methods. The gene and species annotation adopted in this study uses the four letters code described in Table 1. The ORF teph_1_h00580, was chosen as outgroup due to the strong dissimilarity of its amino acid sequence when compared with those of the remaining members of this gene family

\section{Reconstruction of the evolutionary history of Haa 1 and} Cup2 orthologues based on gene neighbourhood analysis The grouping of each of the ORFs into a specific cluster of amino acid sequence similarity allows the exploitation of the information on the chromosome environment where the HAA1 and CUP2 orthologues reside. Although the synteny information comprised in the YGOB database [20] already allows such analysis for most of the yeast species examined in this study, the genome sequences of $Z$. bailii species are still lacking in this database as well as the sequences of other species with the genomes currently available (S. paradoxus, S. arboricola, S. bayanus, Kluyveromyces marxianus var. Marxianus, $K$. wickerhamii, $K$. aestuarii and Ashbya aceri). For this reason, and since the combination of phylogenetic and comparative genomic analyses is a more reliable strategy to elucidate the orthologue/paralogue status of homologous genes, the analysis of the chromosome environment where all the $H A A 1$ and CUP2 orthologue sequences reside was performed. Results confirm that these genes share many common neighbours (Fig. 7). Considering that putative Haa1/Cup2 transcription factors of protoploid Saccharomycetaceae species always show a protein size above 540 amino acids (average size of 622 amino acids), it is likely that the $H A A 1 / C U P 2$ ancestral gene would encode a protein with size closer to the $H A A 1$ orthologues. The gene neighbourhood analysis corroborated the indications obtained from classic phylogenetic methodologies that after the WGD event, a single gene lineage comprising the members of the Haa1/Cup2 family gave rise to two sublineages, each comprising the orthologues of $S$. cerevisiae $H A A 1$ and CUP2 genes (Figs. 7 and 8). With the exception

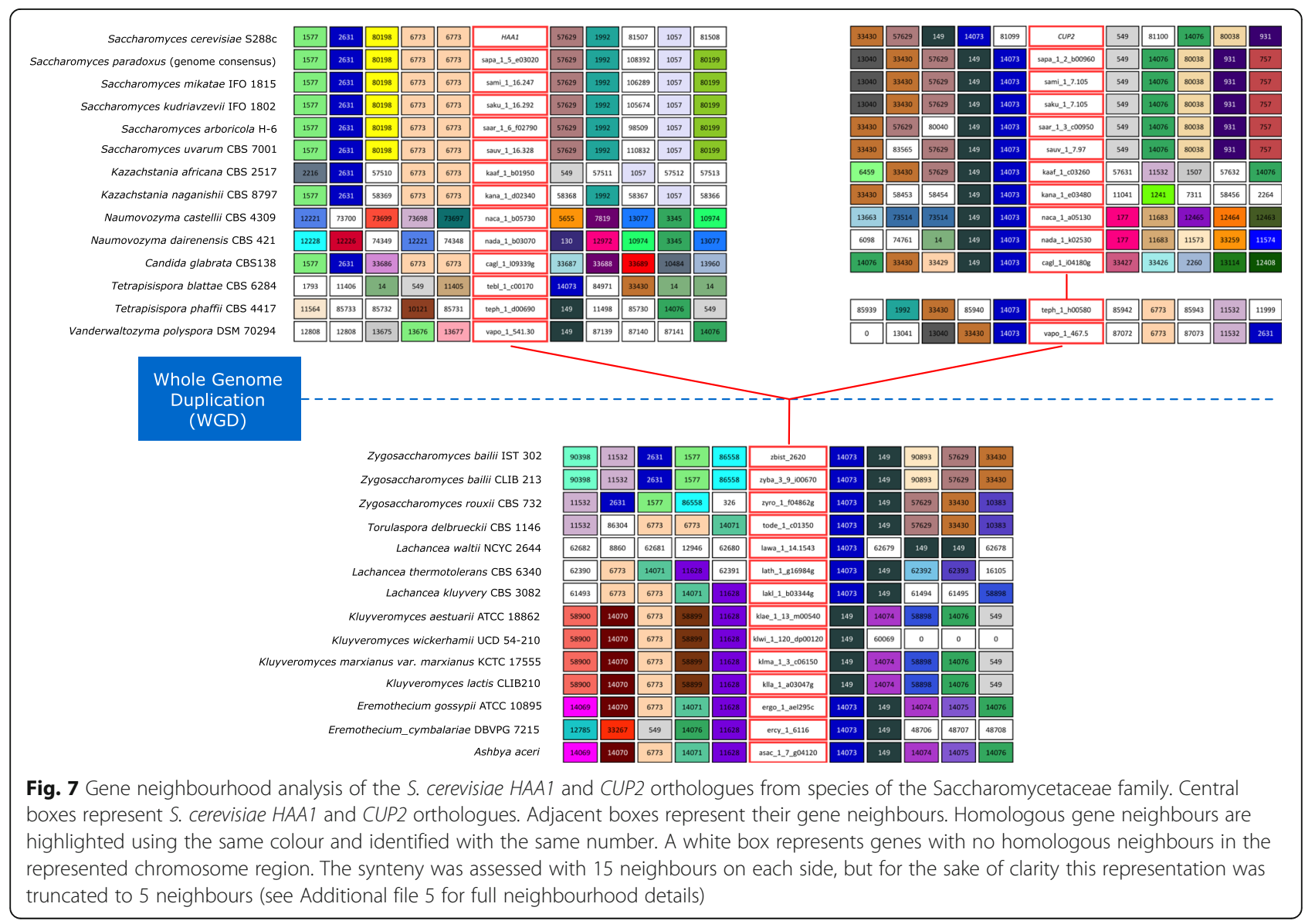




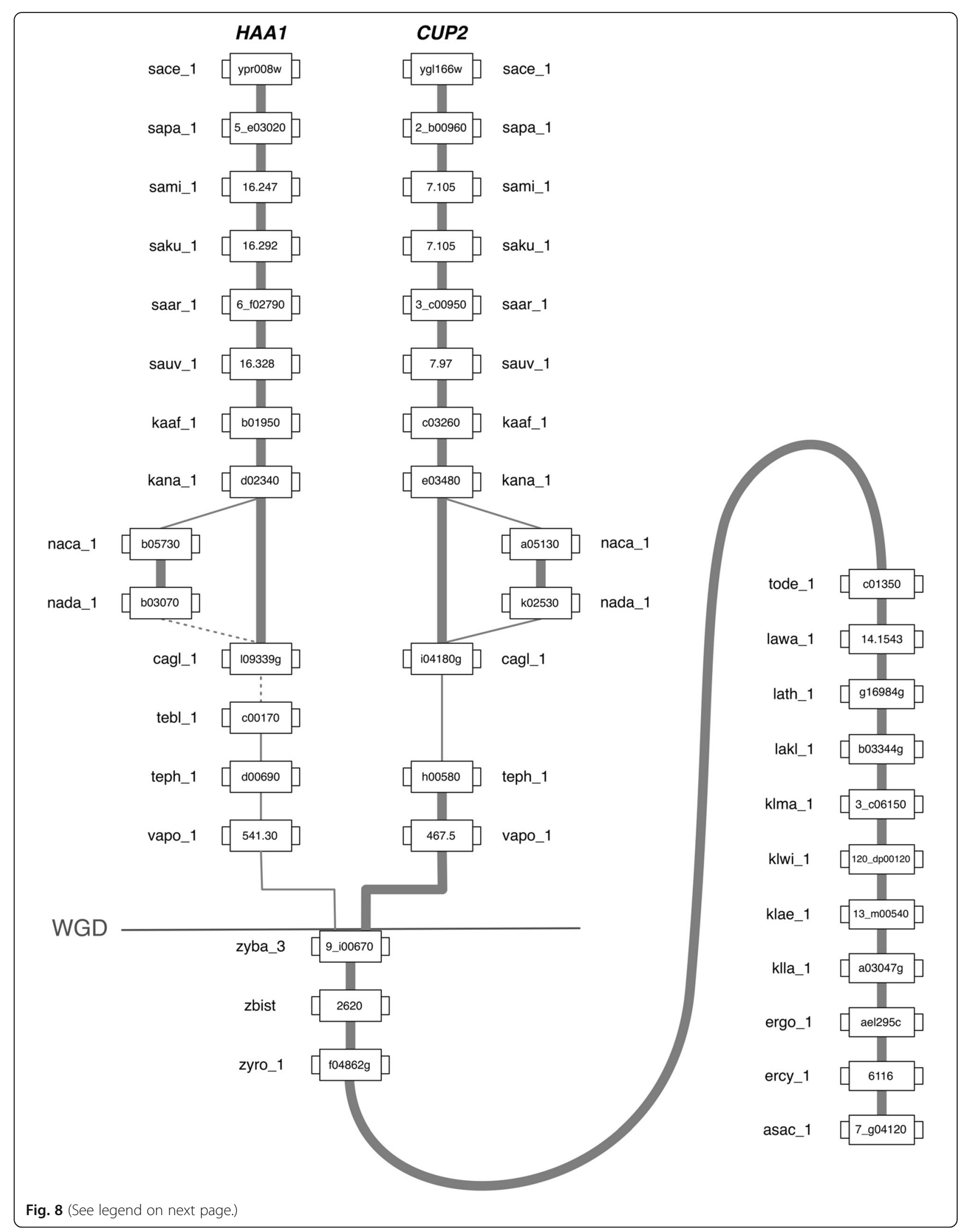


(See figure on previous page.)

Fig. 8 Reconstruction of the evolutionary history of the Haa1 and Cup2 orthologues in Saccharomycetaceae yeasts. Each box represents a gene. Lines connect genes sharing common neighbours. Thick lines connecting genes indicate the existence of stronger synteny evidence. The line labelled as WGD indicates the point in time in the evolution of the Saccharomycetaceae yeast where the Whole Genome Duplication (WGD) event occurred

of the yeast species from Naumovozyma genus, all orthologues encoded in late-divergent post-WGD species share strong synteny (i.e. inside each sub-lineage). However, Vanderwaltozyma and Tetrapisispora species, belonging to early divergent taxonomic genera shortly differentiated after the WGD event, shows that their HAA1 and CUP2 orthologues share scarce synteny with the $S$. cerevisiae HAA1 and CUP2 genes and with other genes encoded in post-WGD species that evolved later, suggesting local genome-shuffling.

The single Haa1/Cup2 orthologue from Z. bailii is also involved in response and tolerance to copper stress

As previously demonstrated by Keller et al. [1], both $S$. cerevisiae BY4741 and derived haa1 $\Delta$ mutant strains are more tolerant to $\mathrm{CuSO}_{4}$ than cup $2 \Delta$ mutant strain that is very susceptible to this metal cation (Fig. 9a). On the other hand, S. cerevisiae BY4741 parental and derived cup $2 \Delta$ mutant strains are remarkably more tolerant to acetic acid than haa1 $\Delta$ mutant (Fig. 9c). Considering the proposed evolutionary history of Haa1 and Cup2 orthologues and their specific physiological functions in $S$. cerevisiae, the hypothesis of whether the sole ZbHaal could be involved in copper tolerance was tested. The heterologous expression of ZbHAA1 in S. cerevisiae cup $2 \Delta$ mutant strain was found to rescue the susceptibility phenotype of the deletion mutant by increasing its tolerance to $\mathrm{CuSO}_{4}$ up to the level of the parental strain (Fig. 9a). Contrasting with these phenotypes, no growth was detected in minimal medium containing $0.15 \mathrm{mM}$ $\mathrm{CuSO}_{4}$, either in S. cerevisiae cup $2 \Delta$ transformed with the cloning vector or in the same background strain expressing ScHAA1 (Fig. 9a). The susceptibility of $Z$. bailii IST302 and derived deletion mutant Zbhaa1A to copper stress was also tested. Differently from the absence of alteration of the copper susceptibility phenotype by the deletion of $S c H A A 1$ in $S$. cerevisiae, the deletion of ZbHAA1 in Z. bailii IST302 led to a marked increased susceptibility to copper (Fig. 9b). These results reinforce the concept that $\mathrm{ZbHaal}$ might have a dual

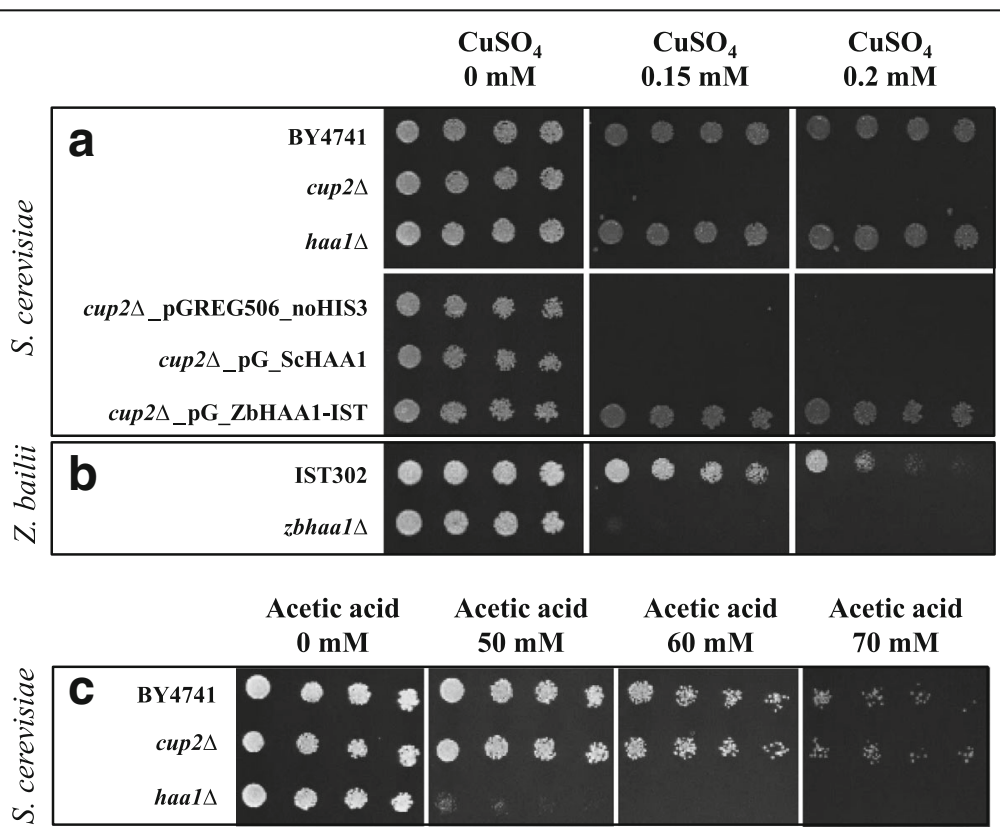

Fig. 9 ZbHaa1 is required for copper tolerance. Susceptibility to copper was compared in a S. cerevisiae BY4741 parental and derived deletion mutants haa $1 \triangle$ and cup2 $\triangle$, in cup2 $\triangle$ expressing the recombinant plasmids PG_ZbHAA1-IST, PG_SCHAA1 or the cloning vector and in $\mathbf{b} Z$. bailii IST302 parental and derived deletion mutant Zbhaa1 $\Delta$ strains. c S. cerevisiae BY4741 parental and derived deletion mutants haa $1 \Delta$ and cup2 $\Delta$ were also compared in what concerns their susceptibility to acetic acid. Cell suspensions with an absorbance at $600 \mathrm{~nm}$ of $0.05 \pm 0.005$ (lane a) and subsequent dilutions of 1:5, 1:10 and 1:20 (lanes b, $c$ and d, respectively) were spotted onto the surface of the appropriate agarized media, supplemented with appropriate concentrations of copper or acetic acid. The images depicted were taken after 3 days of incubation at $30^{\circ} \mathrm{C}$ and are representative of at least three independent experiments 
function, being putatively involved in the regulation of acetic acid (as demonstrated above) and copperresponsive genes as found for its $S$. cerevisiae single orthologues Haa1 and Cup2, respectively.

In order to confirm the hypothesized role of ZbHaa1 in the response to copper, the transcript levels from $S$. cerevisiae metallothionein encoding gene CUP1, that is regulated by Cup2 under copper stress [44], were compared in S. cerevisiae cup $2 \Delta$ mutant strain expressing $Z b H A A 1$, in $S$. cerevisiae parental strain (positive control) and in the derived deletion mutant cup $2 \Delta$ transformed with the cloning vector or expressing ScHAA1 (both used as negative controls). An increase in the mRNA level from CUP1 was observed in cells expressing ZbHAA1 after 1 and $2 \mathrm{~h}$ of exposure to $0.1 \mathrm{mM}$ $\mathrm{CuSO}_{4}$ (Fig. 10). This increase was not detected in $S$. cerevisiae cup $2 \Delta$ mutant strain either transformed with the cloning vector or expressing ScHAA1, demonstrating that $S$. cerevisiae CUP1 gene is regulated by ZbHaa1 under copper stress. Since no homologue of $S$. cerevisiae CUP1 could be identified in Z. bailii IST302 genome sequence, the homologue of $S$. cerevisiae metallothionein encoding gene CRS5, whose expression is dependent on CUP2 upon copper stress [45], was identified in the genome sequence of Z. bailii IST302 (ORF ZBIST_3713, here mentioned as $Z b C R S 5$, Additional file 2). A remarkable increase in the mRNA levels from $Z b C R S 5$ in $Z$. bailii IST302 parental strain was found during the early adaptive response to copper ( $1 \mathrm{~h}$ after sudden exposure to copper), being this activation of $Z b C R S 5$ transcription significantly reduced in the Zbhaa1 $\Delta$ deletion mutant (Fig. 11), indicating that the activation of ZbCRS5 is dependent on ZbHaal in Z. bailii cells under copper stress.

\section{Discussion}

The physiological role of $Z$. bailii transcription factor ZbHaal, homologous to $S$. cerevisiae Haal, in the response and tolerance to acetic acid and copper was examined in this work by exploring functional and evolutionary analyses. It was demonstrated that $\mathrm{ZbHaa1}$ is a functional homologue of ScHaal, playing a role in $Z$. bailii tolerance to acetic acid and to other weak acid food preservatives. As previously reported for ScHaa1, the effect of ZbHaal is more evident for the more hydrophilic short-chain weak acid acetic acid [2]. Moreover, similarly to the increased tolerance to acetic acid resulting from the overexpression of ScHAA1 in S. cerevisiae [46], the expression of an extra copy of $Z b H A A 1$ in $Z$. bailii remarkably increases the tolerance of $Z$. bailii to all the weak acids tested. Furthermore, the involvement of ZbHaal in the transcriptional activation in response to acetic acid stress of $Z$. bailii genes homologous to $S$. cerevisiae Haa1-target genes reinforces the
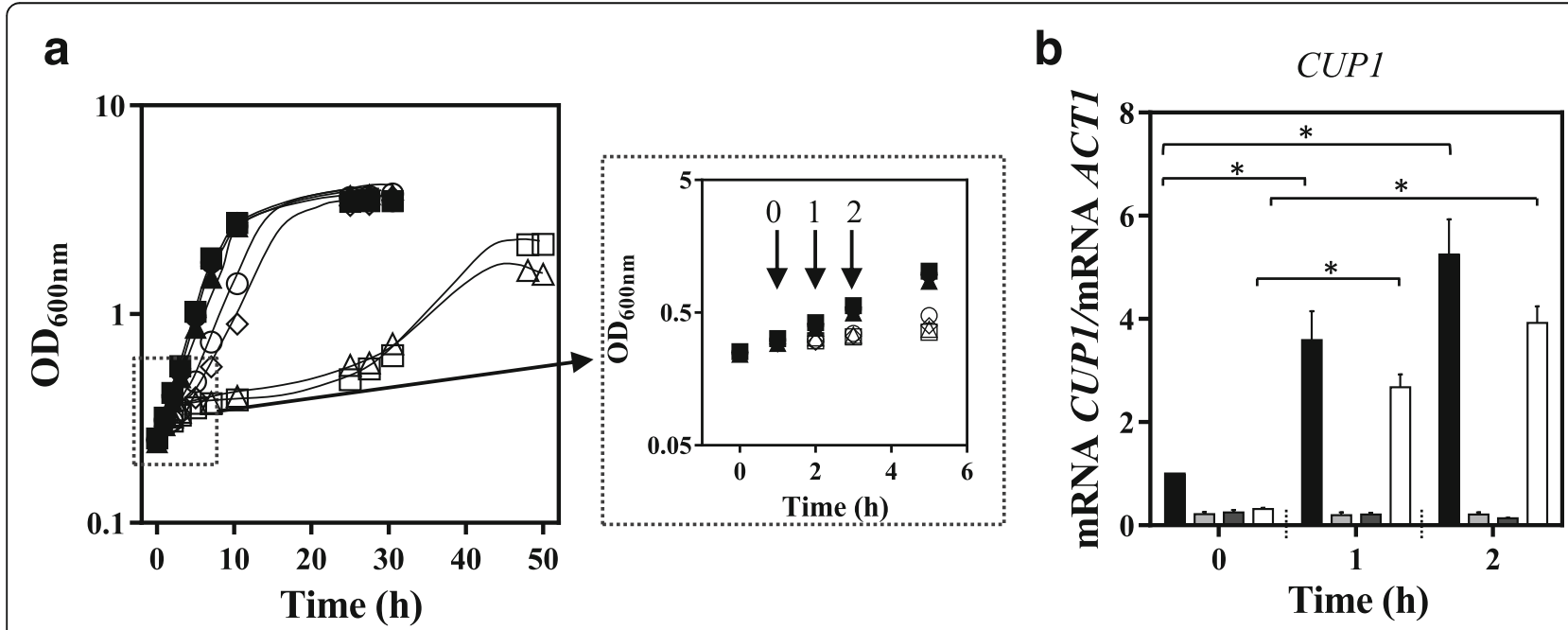

Fig. 10 The expression of ZBHAAT, but not of SCHAA1 gene, in S. cerevisiae cup2 $\triangle$ mutant leads to the activation of transcription from S. cerevisiae Cup2 target gene CUP1. a Growth curves of S. cerevisiae BY4741 parental strain transformed with the cloning vector $(\bullet, 0)$ and of its derived deletion mutant cup2 $\triangle$ expressing the recombinant plasmids pG_ZbHAA1 $(\bullet, \diamond), \operatorname{pG} \_$ScHAA1 $(\boldsymbol{\Lambda}, \Delta)$ or the cloning vector $(\mathbf{\bullet}, \square)$ cultivated in MM4-U (filled symbols). $\mathrm{CuSO}_{4}$ was added after $1 \mathrm{~h}$ of growth in MM4-U to a final concentration of $0.1 \mathrm{mM}$ (empty symbols). For mRNA levels quantification, yeast cells were harvested before $\mathrm{CuSO}_{4}$ supplementation (Time point 0), or 1 or $2 \mathrm{~h}$ after the addition of CuSO ${ }_{4}$ (Time points 1 and 2, respectively). b Comparison of the transcript levels from S. cerevisiae gene CUP1 in time points 0,1 and 2. ACT1 mRNA level was used as an internal control. The mRNA level from CUP1 gene in S. cerevisiae BY4741 transformed with the cloning vector (black bar) in the absence of CuSO (Time point 0) was set as 1 and the transcript levels from CUP1 gene were calculated relative to this control. CUP1 transcript levels in cup2 $\triangle$ transformed with the cloning vector, pG_ScHAA1 or PG_ZbHAA1-IST are represented by light grey, dark grey or white bars, respectively. mRNA values shown are the mean of, at least, three independent experiments. Results were analysed by two-way ANOVA. (*) $p$-value below 0.05 , when comparing the relative mRNA levels in each strain at a given time point 

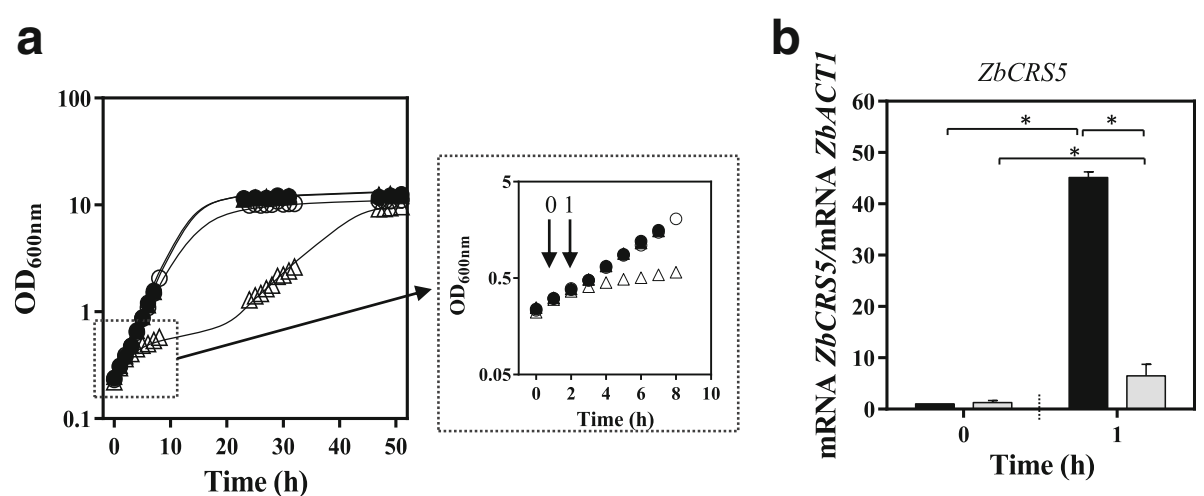

Fig. 11 ZbHaa1 is required for the transcriptional activation of ZbCRS5 gene in copper stressed cells of Z. bailii. a Growth curves of Z. bailii IST302 $(\bullet, 0)$ and of its derived deletion mutant Zbhaar $\Delta(\boldsymbol{\Lambda}, \Delta)$ cultivated in MM medium (filled symbols) or in the same medium supplemented with $\mathrm{CuSO}_{4}$ (empty symbols). $\mathrm{CuSO}_{4}$ was added after $1 \mathrm{~h}$ of growth in $\mathrm{MM}$ medium to a final concentration of $0.08 \mathrm{mM}$. Yeast cells were harvested before $\mathrm{CuSO}_{4}$ supplementation (Time point 0) or $1 \mathrm{~h}$ after $\mathrm{CuSO}_{4}$ addition (Time point 1). b Comparison of the transcript levels from ZbCRS5 in Z. bailii IST302 (dark bars) or in the derived deletion mutant Zbhaal (grey bars) in the absence of $\mathrm{CuSO}_{4}$ (Time point 0) and $1 \mathrm{~h}$ after CuSO 4 supplementation (Time point 1). ZbACT1 mRNA level was used as an internal control. The mRNA level from Z. bailii IST302 gene ZbCRS5 in the absence of $\mathrm{CuSO}_{4}$ (Time point 0 ) was set as 1 and the transcript levels from this gene were calculated relative to this control. mRNA values shown are the mean of, at least, three independent experiments. Results were analysed by two-way ANOVA. $\left(^{*}\right) p$-value below 0.05 , when comparing the relative mRNA levels in each strain at a given time point

concept that ZbHaal is indeed a functional homologue of ScHaal and that the ZbHaa1-regulon is, at least in part, similar to the ScHaa1-regulon described before [4].

The identification of $S$. cerevisiae Haal homologues in Saccharomycetaceae yeast species showed that Z. bailii and all the other pre-WGD species do possess a sole Haal homologue that is also homologous to $S$. cerevisiae Cup2 [1], a transcription factor involved in yeast response and tolerance to high copper concentrations [47]. The phylogenetic and gene neighbourhood analyses of the Haa1 and Cup2 homologues identified among 33 strains of 28 pre- and post-WGD Saccharomycetaceae yeast species allowed outlining their evolutionary history. A clear separation of the Haa1 and Cup2 homologues into three main groups resulted from the analysis: two groups containing either Haa1 or Cup2 orthologues encoded in the genomes of post-WGD yeast species, and a third containing Haa1/Cup2 orthologues from pre-WGD species. The only exception to the evolutionary pattern observed, in which post-WGD yeast species encode two members of the Haa1/Cup2 family in their genomes, is Tetrapisispora blattae that only possesses in the genome one member of this family. Since the genome sequencing was performed with high coverage (above 20X) and assembled into few scaffolds (10), it is likely that this yeast species may indeed encode a single member of this gene family. However, based on the size of the encoded protein (604 amino acids) and on its position in the phylogenetic tree, it was assigned as a Haa1 orthologue, although two neighbour gene families that also reside adjacent to the chromosomal region where the majority of Cup2 orthologues reside were found in its neighbourhood.

The evolutionary analysis performed reinforces the conclusion of previous studies suggesting that $S$. cerevisiae Haa1 and Cup2 are paralogues with origin in the WGD event $[1,19,20]$. After a gene duplication event, functional redundancy of the two duplicates is frequently avoided for their preservation in the genome and, eventually, fixation in the population gene pool [48-50]. Altogether, the indications obtained in this study led us to hypothesize that the sole $Z b H A A 1$ gene could encode a bifunctional transcription factor controlling both the acetic acid and copper stress-response regulons that, upon the WGD event, subfunctionalized and partitioned the independent control of each regulon. In this study, experimental evidences are provided indicating that ZbHaal is indeed also involved in Z. bailii response and tolerance to copper stress. Moreover, the expression of $Z b H A A 1$ in S. cerevisiae cup $2 \Delta$ mutant leads to the transcriptional activation of the metallothionein encoding gene CUP1 that in S. cerevisiae is activated upon copper stress under the dependence of Cup2 transcription factor [44]. Moreover, ZbHAA1 expression in $Z$. bailii significantly increases the transcription of ZbCRS5, a homologue of $S$. cerevisiae CRS5 gene that is also regulated by Cup2 transcription factor in copper-challenged cells [45]. The fact that all genomes of the protoploid yeast species examined in this study encode a single Haa1/Cup2 orthologue suggests that the single Saccharomycetaceae yeast ancestral would have been a bifunctional transcription factor. 
It is recognized that the duplication of transcription factors and/or of their gene targets is one of the most important evolutionary forces driving the evolution of transcriptional regulatory networks, leading to the expansion of existent networks or to the emergence of new ones, as well as allowing the acquisition of novel patterns of gene expression [50-52]. This study shows that the CUP2 orthologues experienced a series of deletion events throughout the evolution of the post-WGD species that led to a progressive decrease in the protein size. This reduction occurred essentially at the level of the transactivation domain while the DNA-binding domain remained highly conserved. Hence, the average protein size of 622 amino acids observed in the Haa1/Cup2 orthologues encoded in the genomes of the protoploid Saccharomycetaceae yeasts was reduced to a total of 341 amino acids in the Cup2 orthologue encoded in the genome of $V$. polysporus, a species that descended from an ancestral yeast that diverged immediately after the WGD event [53]. Further deletions reduced the length of these proteins in late-diverging yeast species, with the $S$. cerevisiae Cup2 transcription factor showing a total size of 225 amino acids. These results support the hypothesis that after the WGD event this bifunctional ancestral gene divided its functions among the daughter duplicates through the acquisition of neutral degenerative mutations. Under this hypothesis, the observed indels in the amino acid sequences of the Cup2 orthologues would be explained by a specific subfunctionalization model, known as Duplication, Degeneration and Complementation [54]. Other cases of subfunctionalization occurring in yeast and consistent with this model have been reported in the literature, for instance, for the paralogue pairs Gal1 and Gal3 [55], Sir2 and Hst1 [56] and Bat1 and Bat2 [57]. The completion of the subfunctionalization process that was in the origin of Haa1 and Cup2 is still unclear. Our results and those reported by Keller et al. [1] show that Haa1 is not involved in S. cerevisiae tolerance to copper. Although Cup2 was recently identified as a determinant of acetic acid tolerance in a quantitative trait loci analysis of pooled segregants that revealed the polygenic nature of high acetic acid tolerance in yeast, suggesting that in superior segregrants the CUP2 allele could take over the function of $H A A 1$ [58], for S. cerevisiae S288c and under the experimental conditions used, we could not find evidences supporting the involvement of Cup2 in acetic acid tolerance. Our study points towards the evolution of both paralogues in a way that each one regulates a subset of the target genes all regulated by the single ancestral bifunctional transcription factor, given that ZbHaal activates $Z$. bailii genes homologous to both $S$. cerevisiae Haa1 and Cup2 target genes under acetic acid or copper-induced stresses. However, apparently, no cross-talk has been observed between both regulators in $S$. cerevisiae [1]. $S$. cerevisiae Haa1 and Cup2 transcription factors recognize different motifs in promoter regions, respectively, 5'-(G/C)(A/C)GG(G/C)G-3'[5] and 5'TC(T) ${ }_{4-6}$ GCTG-3' [59] or 5'-HTHNNGCTGD-3' [60]. In this study it is demonstrated that ZbHaal can activate $S$. cerevisiae Haa1 and Cup2 target genes under acetic acid or copper stresses, respectively, which suggests that $\mathrm{ZbHaa1}$ is apparently able to bind to the promoter regions of all those target genes. We have examined the promoters of the $Z$. bailii genes found in our study to be activated by ZbHaal under acetic acid or copper-induced stresses using the YEASTRACT database [61] and identified, in the promoter region of $\mathrm{ZbHaa1}$ target genes ZbHRK1, ZbHSP30, ZbMSN4, ZbYRO2 and $Z b C R S 5$, the presence of both $S$. cerevisiae Haa1 and Cup2 binding sites, but in ZbTPO3 and ZbYGP1 only the S. cerevisiae Haa1 recognition motif was found. Interestingly, the S. cerevisiae promoters of the Haa1 target genes YGP1, MSN4 and HSP3O and of the Cup2 target gene CRS5 also hold the binding sites for both Cup2 and Haa1 transcription factors. In order to understand how $\mathrm{ZbHaa} 1$ transcription factor regulatory network in $Z$. bailii relates with those regulated in $S$. cerevisiae by Haa1 and Cup 2 transcription factors, it is crucial to determine the full $\mathrm{ZbHaa1}$ regulon in $Z$. bailii and to elucidate the regulatory patterns of the target genes under copper or acetic acid-induced stresses. To get this information, it would be necessary at first to compare the transcriptomes of the parental Z. bailii strain and the mutant deleted for the gene encoding ZbHaal under those stresses and, subsequently, to fully identify the DNA motif(s) recognized by this transcription factor. Such information would provide insights for the understanding on how the DNA binding sequences have changed throughout evolution, and the mechanisms underlying the higher and lower specificity of the different orthologue proteins for the corresponding DNA binding motifs and subsequent transcriptional activation.

\section{Conclusions}

Based on functional and evolutionary analyses, this study demonstrates that the $Z$. bailii transcription factor homologous to $S$. cerevisiae Haa1 (ZbHaa1) is a bifunctional transcription factor, being required for response and tolerance to both acetic acid and copper stresses, and suggests the subfunctionalization of the ancestral Haa1/ Cup2 orthologue after whole genome duplication, originating Haa1 and Cup2 paralogues. In S. cerevisiae, these genes were described as being individually involved in tolerance to acetic acid and copper stresses, respectively. 


\section{Additional files}

Additional file 1: Primers used in this work. (PDF $288 \mathrm{~kb}$ )

Additional file 2: Nucleotide sequences of the Zygosaccharomyces bailii IST302 genes studied. (PDF 105 kb)

Additional file 3: Amino acid sequences of the Haa1 and Cup2 homologues identified in the 28 Saccharomycetaceae yeast species. (PDF 60 kb)

Additional file 4: Phylogenetic analysis of S. cerevisiae Haa1 and Cup2 transcription factors homologues encoded in the genomes of 33 strains of 28 yeast species belonging to the Saccharomycetaceae family. A) Radial phylogram showing the amino acid sequence similarity distances between these 51 full-size proteins. B) Circular cladogram showing the tree topology, with the name of the S. cerevisiae and Z. bailii members indicated. PhyML software suite was used in phylogenetic tree calculation. The gene and species annotation adopted in this study uses the four letters code described in Table 1. (PDF 1465 kb)

Additional file 5: Gene neighbourhood analysis of the S. cerevisiae HAA1 and CUP2 orthologues from species of the Saccharomycetaceae family. Central boxes represent S. cerevisiae HAA1 and CUP2 orthologues. Adjacent boxes represent their gene neighbours. Homologous gene neighbours are highlighted using the same colour and identified with the same number. A white box represents genes with no homologous neighbours in the represented chromosome region. (PDF $2076 \mathrm{~kb}$ )

\section{Abbreviations}

ACRE: Acetic acid responsive element; CuRD: Copper regulatory domain; DBD: DNA binding domain; HPD: Highest Posterior Density; LB: Luria-Bertani; MCMC: Markov chain Monte Carlo; ML: Maximum likelihood; MM: Mineral medium; MPI: Message Passing Interface; ORF: Open reading frame; PCR: Polymerase chain reaction; RT-PCR: Reverse transcription polymerase chain reaction; SGD: Saccharomyces genome database; WGD: Whole genome duplication; YGAP: Yeast genome annotation pipeline; YGOB: Yeast gene order browser; YPD: Yeast extract-peptone-dextrose; YPF: Yeast extract-peptone-fructose

\section{Acknowledgements}

Not applicable.

\section{Funding}

This work was supported by Project contract PTDC/BBB-BEP/0385/2014 through "Fundação para a Ciência e a Tecnologia" (FCT)/MEC (PIDDAC) and PhD and Post-doctoral fellowships SFRH/BPD/73306/2010, SFRH/BPD/ 74618/2010, SFRH/BD/82226/2011 and SFRH/BD/80065/2011 awarded by FCT to MP, PJD, FCR and JFG, respectively. Funding received by iBB-Institute for Bioengineering and Biosciences from FCT (UID/BIO/ 04565/2013) and from Programa Operacional Regional de Lisboa 2020 (Project N. 007317) is acknowledged.

\section{Availability of supporting data}

All the supporting data of this article is included within the article and in its Additional files 1, 2, 3, 4 and 5. Nucleotide sequences of Z. bailii IST302 genes ZbHAA1, ZbHRK1, ZbHSP30, ZbTPO3, ZbMSN4, ZbYGP1, ZbYRO2 and ZbCRS5 have been deposited in GenBank ${ }^{\circledast}$ (http://www.ncbi.nlm.nih.gov) with the accession numbers KX656024, KX656025, KX656026, KX656027, KX656028, KX656029, KX656030 and KX656031, respectively.

\section{Authors' contributions}

MP performed the disruption of Z. bailii IST302 HAA1 homologue, cloning and expression of an extra copy of ZbHAA1 in Z. bailii IST302, susceptibility assays and comparison of mRNA relative levels in S. cerevisiae background strains. PJD performed the phylogenetic and gene neighbourhood analyses of the Haal homologues. FCR performed the comparison of mRNA relative levels in Z. bailii strains. JFG and LL cloned ZbHAA1 and SCHAA1 into pGREG506. MP, PJD and IS-C contributed to the writing of the manuscript. IS-C conceived and coordinated the study. All authors read and approved the final manuscript.

\section{Competing interests}

The authors declare that they have no competing interests.

Consent for publication

Not applicable.

Ethics approval and consent to participate

Not applicable.

Received: 20 September 2016 Accepted: 19 December 2016

Published online: 13 January 2017

\section{References}

1. Keller G, Ray E, Brown PO, Winge DR. Haa1, a protein homologous to the copper-regulated transcription factor Ace1, is a novel transcriptional activator. J Biol Chem. 2001;276:38697-702.

2. Fernandes AR, Mira NP, Vargas RC, Canelhas I, Sá-Correia I. Saccharomyces cerevisiae adaptation to weak acids involves the transcription factor Haalp and Haalp-regulated genes. Biochem Biophys Res Commun. 2005;337:95-103.

3. Mira NP, Palma M, Guerreiro JF, Sa-Correia I. Genome-wide identification of Saccharomyces cerevisiae genes required for tolerance to acetic acid. Microb Cell Fact. 2010;9:79.

4. Mira NP, Becker JD, Sá-Correia I. Genomic expression program involving the Haa1p-regulon in Saccharomyces cerevisiae response to acetic acid. OMICS. 2010;14:587-601.

5. Mira NP, Henriques SF, Keller G, Teixeira MC, Matos RG, Arraiano CM, et al. Identification of a DNA-binding site for the transcription factor Haa1, required for Saccharomyces cerevisiae response to acetic acid stress. Nucleic Acids Res. 2011:39:6896-907.

6. Destruelle M, Holzer $\mathrm{H}$, Klionsky DJ. Identification and characterization of a novel yeast gene: the YGP1 gene product is a highly glycosylated secreted protein that is synthesized in response to nutrient limitation. Mol Cell Biol. 1994:14:2740-54.

7. Takabatake A, Kawazoe N, Izawa S. Plasma membrane proteins Yro2 and Mrh1 are required for acetic acid tolerance in Saccharomyces cerevisiae. Appl Microbiol Biotechnol. 2015;99:2805-14.

8. Goossens A, de La Fuente N, Forment J, Serrano R, Portillo F. Regulation of yeast $\mathrm{H}(+)$-ATPase by protein kinases belonging to a family dedicated to activation of plasma membrane transporters. Mol Cell Biol. 2000;20:7654-61.

9. Piper PW, Ortiz-Calderon C, Holyoak C, Coote P, Cole M. Hsp30, the integral plasma membrane heat shock protein of Saccharomyces cerevisiae, is a stress-inducible regulator of plasma membrane $\mathrm{H}(+)$-ATPase. Cell Stress Chaperones. 1997;2:12-24.

10. Sá-Correia I, Guerreiro JF, Loureiro-Dias MC, Leão C, Côrte-Real M. Zygosaccharomyces. In: Batt CA, Tortorello ML, editors. Encycl. Food Microbiol, vol 3. Elsevier Ltd, Academic Press; 2014. pp. 849-55.

11. Arneborg N, Jespersen $L$, Jakobsen M. Individual cells of Saccharomyces cerevisiae and Zygosaccharomyces bailii exhibit different short-term intracellular pH responses to acetic acid. Arch Microbiol. 2000;174:125-8.

12. Dang TDT, De Maeseneire SL, Zhang BY, De Vos WH, Rajkovic A, Vermeulen A, et al. Monitoring the intracellular pH of Zygosaccharomyces bailii by green fluorescent protein. Int J Food Microbiol. 2012;156:290-5.

13. Guerreiro JF, Mira NP, Sá-Correia I. Adaptive response to acetic acid in the highly resistant yeast species Zygosaccharomyces bailii revealed by quantitative proteomics. Proteomics. 2012;12:2303-18.

14. Rodrigues F, Sousa MJ, Ludovico P, Santos H, Côrte-Real M, Leão C. The fate of acetic acid during glucose co-metabolism by the spoilage yeast Zygosaccharomyces bailii. PLoS One. 2012;7:e52402.

15. Sousa MJ, Miranda L, Corte-Real M, Leão C. Transport of acetic acid in Zygosaccharomyces bailii: effects of ethanol and their implications on the resistance of the yeast to acidic environments. Appl Env Microbiol. 1996;62: 3152-7

16. Lindahl L, Genheden S, Eriksson LA, Olsson L, Bettiga M. Sphingolipids contribute to acetic acid resistance in Zygosaccharomyces bailii. Biotechnol Bioeng. 2016;113:744-53

17. Palma M, Roque F de C, Guerreiro JF, Mira NP, Queiroz L, Sá-Correia I. Search for genes responsible for the remarkably high acetic acid tolerance of a Zygosaccharomyces bailii-derived interspecies hybrid strain. BMC Genomics. 2015;16:1070 
18. Berry DB, Gasch AP. Stress-activated genomic expression changes serve a preparative role for impending stress in yeast. Mol Biol Cell. 2008;19:4580-7.

19. Dietrich FS, Voegeli S, Brachat S, Lerch A, Gates K, Steiner S, et al. The Ashbya gossypii genome as a tool for mapping the ancient Saccharomyces cerevisiae genome. Science. 2004;304:304-7.

20. Byrne KP, Wolfe KH. The Yeast Gene Order Browser: combining curated homology and syntenic context reveals gene fate in polyploid species. Genome Res. 2005;15:1456-61.

21. Gordon JL, Armisén D, Proux-Wéra E, ÓhÉigeartaigh SS, Byrne KP, Wolfe KH. Evolutionary erosion of yeast sex chromosomes by mating-type switching accidents. Proc Natl Acad Sci U S A. 2011;108:20024-9.

22. Galeote V, Bigey F, Devillers H, Neuvéglise C, Dequin S. Genome Sequence of the Food Spoilage Yeast Zygosaccharomyces bailii CLIB 213 ${ }^{\top}$. Genome Announc. 2013;1:e00606-13.

23. Wolfe KH, Shields DC. Molecular evidence for an ancient duplication of the entire yeast genome. Nature. 1997;387:708-13.

24. Jansen G, Wu C, Schade B, Thomas DY, Whiteway M. Drag\&Drop cloning in yeast. Gene. 2005;344:43-51.

25. Kuwayama H, Obara S, Morio T, Katoh M, Urushihara H, Tanaka Y. PCRmediated generation of a gene disruption construct without the use of DNA ligase and plasmid vectors. Nucleic Acids Res. 2002;30:E2.

26. Shevchuk NA, Bryksin AV, Nusinovich YA, Cabello FC, Sutherland M, Ladisch S. Construction of long DNA molecules using long PCR-based fusion of several fragments simultaneously. Nucleic Acids Res. 2004;32:e19.

27. Branduardi $P$, Valli M, Brambilla L, Sauer M, Alberghina L, Porro D. The yeast Zygosaccharomyces bailii: a new host for heterologous protein production, secretion and for metabolic engineering applications. FEMS Yeast Res. 2004; 4:493-504.

28. Amin-ul Mannan M, Sharma S, Ganesan K. Total RNA isolation from recalcitrant yeast cells. Anal Biochem. 2009;389:77-9.

29. Livak KJ, Schmittgen TD. Analysis of relative gene expression data using real-time quantitative PCR and the $2^{-\Delta \Delta C T}$ method. Methods. 2001;25:402-8.

30. Kurtzman CP. Phylogenetic circumscription of Saccharomyces, Kluyveromyces and other members of the Saccharomycetaceae, and the proposal of the new genera Lachancea, Nakaseomyces, Naumovia, Vanderwaltozyma and Zygotorulaspora. FEMS Yeast Res. 2003;4:233-45.

31. Tatusova TA, Madden TL. BLAST 2 Sequences, a new tool for comparing protein and nucleotide sequences. FEMS Microbiol Lett. 1999:174:247-50.

32. Edgar RC. MUSCLE: multiple sequence alignment with high accuracy and high throughput. Nucleic Acids Res. 2004;32:1792-7.

33. Waterhouse AM, Procter JB, Martin DMA, Clamp M, Barton GJ. Jalview Version 2-a multiple sequence alignment editor and analysis workbench. Bioinformatics. 2009:25:1189-91.

34. Ronquist F, Huelsenbeck JP. MrBayes 3: Bayesian phylogenetic inference under mixed models. Bioinformatics. 2003:19:1572-4.

35. Huelsenbeck JP, Ronquist F. MRBAYES: Bayesian inference of phylogenetic trees. Bioinformatics. 2001:17:754-5.

36. Paradis E, Claude J, Strimmer K. APE: analyses of phylogenetics and evolution in R language. Bioinformatics. 2004;20:289-90.

37. Felsenstein J. PHYLIP - phylogeny inference package (version 3.2). Cladistics. 1989:5:164-6.

38. Huson DH, Richter DC, Rausch C, Dezulian T, Franz M, Rupp R. Dendroscope: An interactive viewer for large phylogenetic trees. BMC Bioinformatics. 2007; 8:460

39. Grothendieck G. sqldf: Perform SQL Selects on R Data Frames. R package version 0.4-10. 2014. http://cran.r-project.org/package=sqldf.

40. Dias PJ, Seret M-L, Goffeau A, Correia IS, Baret PV. Evolution of the 12spanner drug: $\mathrm{H}+$ antiporter DHA1 family in hemiascomycetous yeasts. OMICS. 2010;14:701-10

41. Seret M-L, Diffels JF, Goffeau A, Baret PV. Combined phylogeny and neighborhood analysis of the evolution of the $A B C$ transporters conferring multiple drug resistance in hemiascomycete yeasts. BMC Genomics. 2009; 10:459.

42. Gelman A, Rubin DB. Inference from iterative simulation using multiple sequences. Stat Sci. 1992;7:457-72.

43. Brooks SP, Gelman A. General methods for monitoring convergence of iterative simulations. J Comput Graph Stat. 1998;7:434-55.

44. Thiele DJ. ACE1 regulates expression of the Saccharomyces cerevisiae metallothionein gene. Mol Cell Biol. 1988;8:2745-52.

45. Culotta VC, Howard WR, Liu XF. CRS5 encodes a metallothionein-like protein in Saccharomyces cerevisiae. J Biol Chem. 1994;269:25295-302.
46. Tanaka K, Ishii Y, Ogawa J, Shima J. Enhancement of acetic acid tolerance in Saccharomyces cerevisiae by overexpression of the HAA1 gene, encoding a transcriptional activator. Appl Environ Microbiol. 2012;78:8161-3.

47. Buchman C, Skroch P, Welch J, Fogel S, Karin M. The CUP2 gene product, regulator of yeast metallothionein expression, is a copper-activated DNAbinding protein. Mol Cell Biol. 1989;9:4091-5.

48. Voordeckers K, Brown CA, Vanneste K, van der Zande E, Voet A, Maere S, et al. Reconstruction of ancestral metabolic enzymes reveals molecular mechanisms underlying evolutionary innovation through gene duplication. PLoS Biol. 2012;10:e1001446.

49. Langkjaer RB, Cliften PF, Johnston M, Piskur J. Yeast genome duplication was followed by asynchronous differentiation of duplicated genes. Nature. 2003:421:848-52

50. Conant GC, Wolfe KH. Turning a hobby into a job: how duplicated genes find new functions. Nat Rev Genet. 2008;9:938-50.

51. Li H, Johnson AD. Evolution of transcription networks-lessons from yeasts. Curr Biol. 2010;20:R746-53.

52. Voordeckers K, Pougach K, Verstrepen KJ. How do regulatory networks evolve and expand throughout evolution? Curr Opin Biotechnol. 2015;34: 180-8.

53. Scannell DR, Frank AC, Conant GC, Byrne KP, Woolfit M, Wolfe KH. Independent sorting-out of thousands of duplicated gene pairs in two yeast species descended from a whole-genome duplication. Proc Natl Acad Sci U S A. 2007:104:8397-402.

54. Force A, Lynch M, Pickett FB, Amores A, Yan YL, Postlethwait J. Preservation of duplicate genes by complementary, degenerative mutations. Genetics. 1999:151:1531-45

55. Hittinger CT, Carroll SB. Gene duplication and the adaptive evolution of a classic genetic switch. Nature. 2007:449:677-81.

56. Froyd CA, Rusche LN. The duplicated deacetylases Sir2 and Hst1 subfunctionalized by acquiring complementary inactivating mutations. Mol Cell Biol. 2011;31:3351-65.

57. Colón M, Hernández F, López K, Quezada H, González J, López G, et al. Saccharomyces cerevisiae Bat1 and Bat2 aminotransferases have functionally diverged from the ancestral-like Kluyveromyces lactis orthologous enzyme. PLoS One. 2011;6:e16099.

58. Meijnen J-P, Randazzo P, Foulquié-Moreno MR, van den Brink J, Vandecruys $P$, Stojiljkovic M, et al. Polygenic analysis and targeted improvement of the complex trait of high acetic acid tolerance in the yeast Saccharomyces cerevisiae. Biotechnol Biofuels. 2016;9:5.

59. Evans CF, Engelke DR, Thiele DJ. ACE1 transcription factor produced in Escherichia coli binds multiple regions within yeast metallothionein upstream activation sequences. Mol Cell Biol. 1990;10:426-9.

60. Koch KA, Thiele DJ. Autoactivation by a Candida glabrata copper metalloregulatory transcription factor requires critical minor groove interactions. Mol Cell Biol. 1996;16:724-34.

61. Teixeira MC, Monteiro P, Jain P, Tenreiro S, Fernandes AR, Mira NP, et al. The YEASTRACT database: a tool for the analysis of transcription regulatory associations in Saccharomyces cerevisiae. Nucleic Acids Res. 2006;34:D446-51.

\section{Submit your next manuscript to BioMed Central and we will help you at every step:}

- We accept pre-submission inquiries

- Our selector tool helps you to find the most relevant journal

- We provide round the clock customer support

- Convenient online submission

- Thorough peer review

- Inclusion in PubMed and all major indexing services

- Maximum visibility for your research

Submit your manuscript at www.biomedcentral.com/submit 